Louisiana State University

LSU Digital Commons

Faculty Publications

Department of Biological Sciences

$5-15-2019$

\title{
Social plasticity in the fish brain: Neuroscientific and ethological aspects
}

\author{
Karen Maruska \\ Louisiana State University \\ Marta C. Soares \\ Universidade do Porto, Centro de Investigação em Biodiversidade e Recursos Genéticos \\ Monica Lima-Maximino \\ Universidade do Estado do Para \\ Diógenes Henrique de Siqueira-Silva \\ Universidade Federal do Sul e Sudeste do Pará \\ Caio Maximino \\ Grupo de Pesquisas em Neuropsicofarmacologia e Psicopatologia Experimental
}

Follow this and additional works at: https://digitalcommons.Isu.edu/biosci_pubs

\section{Recommended Citation}

Maruska, K., Soares, M., Lima-Maximino, M., Henrique de Siqueira-Silva, D., \& Maximino, C. (2019). Social plasticity in the fish brain: Neuroscientific and ethological aspects. Brain Research, 1711, 156-172.

https://doi.org/10.1016/j.brainres.2019.01.026

This Article is brought to you for free and open access by the Department of Biological Sciences at LSU Digital Commons. It has been accepted for inclusion in Faculty Publications by an authorized administrator of LSU Digital Commons. For more information, please contact ir@lsu.edu. 
Review

\title{
Social plasticity in the fish brain: Neuroscientific and ethological aspects
}

\author{
Karen Maruska $^{\mathrm{a}, 1}$, Marta C. Soares ${ }^{\mathrm{b}, 1}$, Monica Lima-Maximino ${ }^{\mathrm{c}, \mathrm{d}}$, \\ Diógenes Henrique de Siqueira-Silva ${ }^{\mathrm{e}, \mathrm{f}}$, Caio Maximino ${ }^{\mathrm{d}, \mathrm{e}, *}$ \\ ${ }^{a}$ Department of Biological Sciences, Louisiana State University, Baton Rouge, USA \\ ${ }^{\mathrm{b}}$ Centro de Investigação em Biodiversidade e Recursos Genéticos - CIBIO, Universidade do Porto, Vairão, Portugal \\ ${ }^{\mathrm{c}}$ Laboratório de Biofísica e Neurofarmacologia, Universidade do Estado do Pará, Campus VIII, Marabá, Brazil \\ ${ }^{\mathrm{d}}$ Grupo de Pesquisas em Neuropsicofarmacologia e Psicopatologia Experimental, Brazil \\ e Laboratório de Neurociências e Comportamento "Frederico Guilherme Graeff", Universidade Federal do Sul e Sudeste do Pará, Marabá, Brazil \\ ${ }^{\mathrm{f}}$ Grupo de Estudos em Reprodução de Peixes Amazônicos, Universidade Federal do Sul e Sudeste do Pará, Marabá, Brazil
}

\section{H I G H L I G H T S}

- Social organization varies across fish species.

- Good models to study social plasticity.

- Participation of monoamines, neuropeptides, and cortisol.

- Molecules of neuroplasticity participate in consolidation of social plasticity.

\section{A R T I C L E I N F O}

\section{Keywords:}

Brain plasticity

Cichlids

Cleanerfish

Social plasticity

Social decision making network

Zebrafish

\begin{abstract}
A B S T R A C T
Social plasticity, defined as the ability to adaptively change the expression of social behavior according to previous experience and to social context, is a key ecological performance trait that should be viewed as crucial for Darwinian fitness. The neural mechanisms for social plasticity are poorly understood, in part due to skewed reliance on rodent models. Fish model organisms are relevant in the field of social plasticity for at least two reasons: first, the diversity of social organization among fish species is staggering, increasing the breadth of evolutionary relevant questions that can be asked. Second, that diversity also suggests translational relevance, since it is more likely that "core" mechanisms of social plasticity are discovered by analyzing a wider variety of social arrangements than relying on a single species. We analyze examples of social plasticity across fish species with different social organizations, concluding that a "core" mechanism is the initiation of behavioral shifts through the modulation of a conserved "social decision-making network", along with other relevant brain regions, by monoamines, neuropeptides, and steroid hormones. The consolidation of these shifts may be mediated via neurogenomic adjustments and regulation of the expression of plasticity-related molecules (transcription factors, cell cycle regulators, and plasticity products).
\end{abstract}

\section{Introduction}

The ability to adapt to changing social environments is a crucial characteristic of biological systems; social plasticity, defined "as the ability to adaptively change the expression of social behavior according to previous experience and to social context" (Teles et al., 2016) is a key ecological performance trait that should be viewed as crucial for Darwinian fitness (Taborsky and Oliveira, 2012). The neural mechanisms for social plasticity are poorly understood, in part due to over-reliance on rodent models (e.g., Krishnan et al., 2007; Curley et al., 2011; but see important work on estrildid finches - e.g., Goodson and Kingsbury, 2011; Goodson et al., 2012) and examination of only a single sex within a species. In principle, these mechanisms involve the modulation of the activity of the social decision-making brain network (O'Connell and Hofmann, 2012a) and other relevant brain nuclei on the short term - by neuromodulators (e.g., neuropeptides and monoamines) and hormones

* Corresponding author at: Laboratório de Neurociências e Comportamento - Instituto de Estudos em Saúde e Biológicas, Universidade Federal do Sul e Sudeste do Pará, Unidade III, Av. dos Ipês, S/N, s/ CEP, Bairro Cidade Jardim, Marabá, PA, Brazil.

E-mail address: cmaximino@unifesspa.edu.br (C. Maximino).

${ }^{1} \mathrm{KM}$ and MCS contributed equally to this paper as co-first authors. 
(eg., sex steroids and glucocorticoids) - and on the long term - by modulating gene expression patterns across the network (Oliveira, 2009; Taborsky and Oliveira, 2012; Cardoso et al., 2015a,b,c,d).

The present review summarizes ongoing research on social plasticity in the fish brain. Fish model organisms are relevant and an ideal vertebrate group to examine social plasticity for at least two reasons: first, the diversity of social organization between fish species is staggering, increasing the breadth of evolutionary relevant questions that can be addressed. Second, that diversity also suggests translational relevance, since it is more likely that "core" mechanisms of social plasticity are discovered by examining a wider variety of social arrangements than relying on a single species. Both issues are discussed in Sections 2 to 4. We proceed, in Sections 5 and 6, by discussing research on social and reproductive status as triggers for plasticity, and examining sensory and cognitive aspects of social plasticity in fishes. The specific example of cleanerfish, which exhibit mutualism but is currently under-studied in behavioral and molecular neuroscience, is analyzed further in Section 6 , along with the role of brain size in social plasticity in guppies. We hope to demonstrate that, from cichlids to poeciliids (e.g., livebearers such as swordtails, mollies, and guppies), from zebrafish to cleanerfish, the variety of social interaction networks observed among fishes is of interest to both evolutionary neuroscientists and behavioral neuroscientists interested in describing the core mechanisms regulating and driving social plasticity.

\section{Fish as models in the neurosciences}

While a great deal of work on social plasticity of the brain has been made using rodents, this strict focus risks missing opportunities to answer questions on the evolution of social plasticity (Panksepp et al., 2002; Striedter et al., 2014; Taborsky and Oliveira, 2012), as well as the rich variety of social environments that fish occupy (Keenlyside, 1979). The use of rodents is certainly relevant due to the phylogenetic position occupied by these animals in relation to humans, but can overlook important variants of social organization that exist in fishes. Indeed, more than 30,000 species of fishes are estimated to occupy both marine and freshwater habitats (http://www.coml.org/) (Nelson et al., 2016). These species occupy different social niches (Section 3), and include single fishes with solitary living and territorial mosaics, animals which establish male-female pairs, animals which live in small groups, animals which form shoals (individuals moving together as a group, but may orient in different directions) and schools (individuals in the shoal all oriented in the same direction), and many other varieties of social organizations (Keenlyside, 1979). Identifying how these different social societies impact brain and behavior, and how changing social environments alter these domains, is an important question to be exploited in the field of social plasticity (Fig. 1).

It has been suggested (Gerlai, 2014; Kas et al., 2011) that increasing the breadth of species used in biomedical research "can robustly enhance our ability to identify biological features and mechanisms that are relevant to the studied behavioral phenomena" (Gerlai, 2014, p. $55)$. The choice of species and model organisms, in the case of the neurosciences, is usually guided by practical advantages (including fertility, throughput, and developmental speed), the existence of wellestablished research communities and data availability (including genomic and transcriptomic data), and the amenability to undertake genetic manipulations and relative simplicity of the nervous system (Maximino et al., 2015). In addition to using well-established model organisms, behavioral neuroscience can benefit from focusing on other, carefully chosen species to amplify the field of discovery and increase translational relevance (Gerlai, 2014; Hall et al., 2014; Maximino et al., 2015). In the context of evolutionary neuroscience, Striedter et al. (2014) used the term "reference species" that meant "carefully selected species from phylogenetically widely spaced vertebrate and invertebrate groups". These reference species are not "models for some other species, but [...] a basis for comparisons that may reveal both similarities and differences" (Striedter et al., 2014, p. 5), ultimately increasing translational relevance by "allowing one to identify common features across species [that are likely to be] shared not just among the studied laboratory organisms but also with humans" (Gerlai, 2014, p. 55). In fact, historically, many of the most significant discoveries allowing the field of basic neuroscience to advance were made in diverse taxa ranging from invertebrates (e.g. squid, Aplysia, crustaceans) to vertebrates (e.g. fishes, frogs, mammals). A similar approach to other fields of neuroscience can benefit the field by comparing taxa to infer how variations in one domain (e.g., gene expression, connectivity, activation patterns) relates to variation in behavior. Of relevance to the question of social plasticity, fish species can be used to understand how variations in social environment impact variations in behavior and brain structure and function (Soares et al., 2018a).

One advantage of using fishes to better understand social plasticity of the vertebrate brain is the ability to study species in a naturalistic context; something rarely achieved in other social vertebrate models such as rodents. Studying fish social behavior in the wild or in laboratory settings that include salient sensory, environmental, and social factors is crucial for discovering accurate neurobiological mechanisms as well as the selective pressures leading to evolutionary adaptations. Because many aspects of neural function are conserved, investigations in amenable systems like fishes have and will continue to provide valuable insights for biomedical applications. Recent advances in genomic and genetic tools for different fish species also increase their utility in social neuroscience. Thus, by abiding to Krogh's principle that for most biological problems, there exists a species that is ideally suited (Krogh, 1929), the diversity of fish species becomes a cornucopia of possibilities for knowledge advances. This includes promise for better understanding mechanisms of and treatments for reproductive, endocrine, neuroendocrine, and neurological disorders in humans that can be influenced by the social environment.

Fish are also excellent reference species to study social plasticity because their brains are admirably plastic. Neural plasticity can involve structural changes, such as alterations in cell population size or connectivity between different nuclei by changing axonal growth and survival or dendritic synaptic connections (Cline, 2001). In contrast to mammals, in which neurogenesis is very limited in adulthood, the formation of new neurons continues throughout the fish's entire life (Zupanc and Sîrbulescu, 2011). Continuing expression of growth-associated protein-43 (gap-43), a marker of axonogenesis, in the brains of coho salmon Oncorhynchus kisutch (Ebbeson and Braithwaite, 2012), suggests that connectivity also changes throughout adulthood. Moreover, heightened plasticity is observed at critical periods of development, such as those associated with leaving fresh water and migrating to the ocean in salmon such as Salmo salar and Onchorhynchus sp. In these species, important behavioral preparations in this transition period include olfactory imprinting on their natal stream and switching from territorial to schooling behavior; these changes are accompanied by sequential changes in structure reorganization, and increased neuronal differentiation, neurogenesis, axonogenesis, and synaptogenesis (reviewed in Ebbeson and Braithwaite, 2012). Finally, the high adult neurogenesis in fish also facilitate high levels of neuronal regeneration: after injury of nervous tissue, a massive surge of apoptotic cell death occurs at the lesion site, followed by a marked increase in cell proliferation and neurogenesis. There is also evidence for structural reorganization and neurogenesis related to the social environment, including social isolation, in several fish species (Sorensen et al., 2007; Maruska et al., 2012; Dunlap et al., 2013). The exquisite plasticity of the fish brain suggests that this group could represent interesting reference species and/or model organisms in the study of the social plasticity of the brain.

Further, fishes are becoming valuable models to study impacts of anthropogenic noise, pollution, and climate change on sensory and brain function (Ashur et al., 2017; Braun, 2015; Fisher and Oleksiak, 2007; Lai et al., 2017), with important consequences for management 

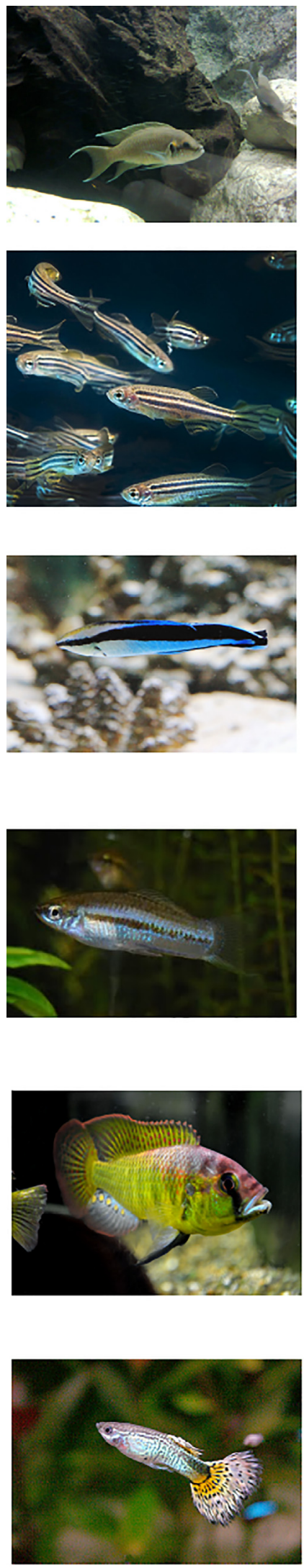

py (Poecilia reticulata Peters 1859)

- Model organism in behavioral ecology

- Assortative mating, mate choice made by females

- Brain morphology plasticity (at the lifehistory and inter-generational levels) due to sexual conflict and dominance contests

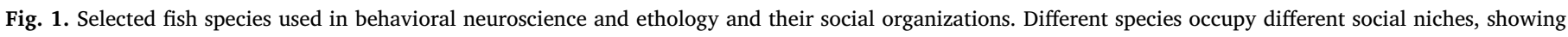
potential to investigate one aspect of social plasticity. 
and conservation. Sensory cues play an integral role in the daily lives and survival of marine and freshwater organisms, including influences on homing, settlement, predator detection and evasion, foraging, conspecific social interactions, and reproductive interactions. Ocean acidification, as a consequence of climate change and pollution, directly affects the performance of sensory systems of marine organisms, including chemosensation, acoustic detection, and vision (review in Ashur et al., 2017). Sound pollution (anthropogenic noise) disrupts both the octavolateralis systems of fishes (which include the vestibular, auditory, lateral line and electrosensory systems) and the sonic environment that provide ecological and ethological cues for fish behavior (review in Braun, 2015). These impacts on systems which show critical social plasticity are beginning to be understood, and studying these in diverse fish species have important ecological and economic consequences, particularly in identifying how fishes may or may not be able to adapt to a changing world.

In addition to increasing possibilities to understand social plasticity, fish models can also increase translational relevance for research in social behavior (Oliveira, 2009; Soares et al., 2018a). This is relevant, because human sociality is crucial for mental health, and social stressors represent a very important source of suffering that can lead to mental disorders (Soares et al., 2018b). Moreover, alterations in social behavior are also observed in different disorders, including social anxiety disorder, autism, Williams syndrome, reactive attachment disorder, and disinhibited attachment disorder (Kennedy and Adolphs, 2012). One caveat to keep in mind when using a comparative approach is that fishes have different sensory abilities and live in an aquatic environment with sensory transmission characteristics that differ from those in air. Thus, the species sensory 'umwelt' will influence their social behaviors and should be considered when making translational applications (von Uexküll, 1926). However, the use of relevant model organisms and reference species, including fish, is important to understand the value and expression of social behavior and the role of genes and the (social) environment interactions in shaping mental disorders (Huhman, 2006; Lim et al., 2005; McOmish et al., 2014; Soares et al., 2018a,b).

\section{The social brain of fish}

Across vertebrates, social behavior is ultimately controlled by the brain. A neural "survival" circuit involved in both reward and sociality, termed the "social decision making network" (SDMN; Fig. 2), was proposed as a framework for testing hypotheses on the neural control of context-dependent behaviors. This network encompasses both the social behavior network and mesolimbic reward system, both of which include a series of brain regions that regulate and integrate responses to salient stimuli (including social and non-social stimuli) (O'Connell and Hofmann 2011). The SDMN involves, in mammals, the lateral septum, extended medial amygdala and bed nucleus of the stria terminalis, preoptic area/paraventricular nucleus (POA/PVN), anterior hypothalamus, ventromedial hypothalamus, and periaqueductal gray area, as well as six areas of the mesolimbic reward system - the striatum, nucleus accumbens, ventral pallidum, basolateral amygdala, hippocampus, and ventral tegmental area (Fig. 2). This network is involved in multiple forms of social behavior, including sexual behavior and courtship, aggression, and parental care, and its nodes are reciprocally connected (Goodson 2005; O'Connell and Hofmann, 2011). By definition, these nodes also express sex hormone receptors (Forlano and Bass, 2011; O'Connell and Hofmann, 2011, 2012).

Nodes of the SDMN are identified in teleost fish, although for many of them only partial homologies have been established and many remain undefined, debated, or controversial (cf. Soares et al., 2018a for a review; Goodson and Kingsbury, 2013) (Table 1). This is primarily due to the differences in forebrain development between teleosts (eversion) and tetrapods (evagination). In all ray-finned fishes, the outward folding, or eversion, of the solid telencephalic lobes results in
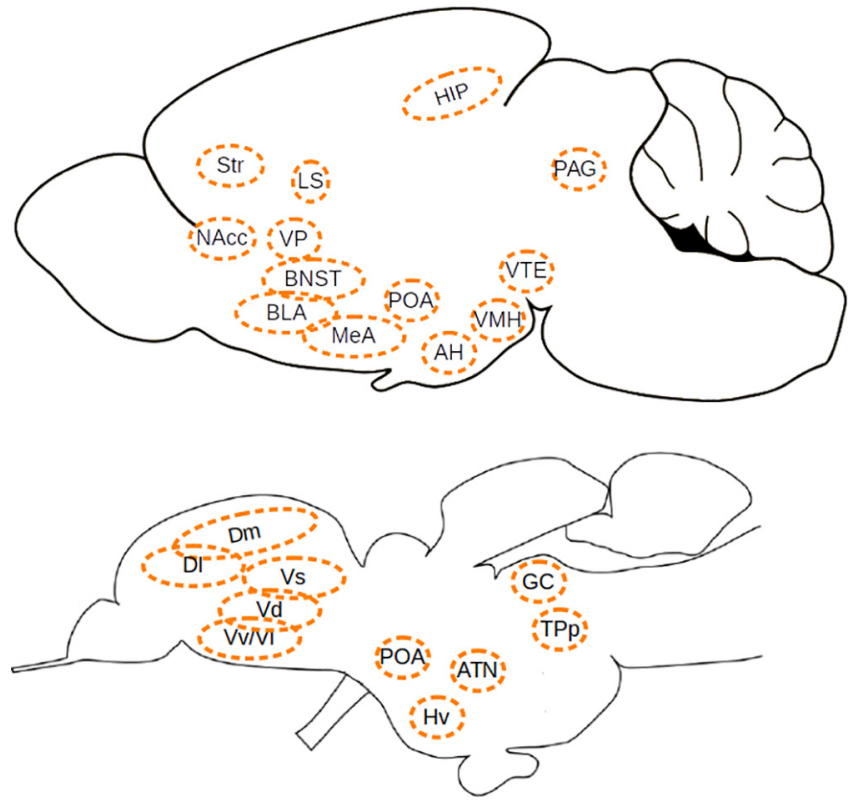

Fig. 2. The social decision-making network (SDMN) of rodents (top) and fish (bottom). Abbreviations: LS - lateral septum; BNST - bed nucleus of the stria terminalis; meAMY - medial amygdala; VMH - ventromedial hypothalamus; $\mathrm{AH}$ - anterior hypothalamus; PAG - periaqueductal gray area; Dm - medial zone of the dorsal telencephalon; Dl - lateral zone of the dorsal telencephalon; Vs - supracommissural zone of the ventral telencephalon; Vd - dorsal zone of the ventral telencephalon; $\mathrm{Vv}$ - ventral zone of the ventral telencephalon; $\mathrm{Vl}$ lateral zone of the ventral telencephalon; POA - preoptic area; Hv - ventral hypothalamus; ATN - anterior tuberal nucleus; TPp - posterior tuberculum.

Table 1

Putative homologous brain regions between teleost fishes and mammals. Note that putative mammalian homologs are only "in part" for many nuclei and are based on the following references. The teleost homolog of the mammalian ventral pallidum is unclear and not listed. Abbreviations: ATn, anterior tuberal nucleus; Dl, lateral part of dorsal telencephalon; Dm, medial part of dorsal telencephalon; PAG/CG, periaqueductal gray/central gray; POA, preoptic area; TPp, periventricular nucleus of posterior tuberculum; Vc, central part of ventral telencephalon; Vd, dorsal part of ventral telencephalon; Vp, postcommissural part of ventral telencephalon; Vs, supracommissural part of ventral telencephalon; Vv, ventral part of ventral telencephalon; VTn, ventral tuberal nucleus.

\begin{tabular}{ll}
\hline Teleost Region & Putative Mammalian Homolog \\
\hline Dm & Pallial amygdala \\
Dl & Medial pallium/hippocampus \\
Vv & Septum/External globus pallidus \\
Vd & Striatum/basal ganglia/nucleus accumbens \\
Vc & Striatum \\
Vs/Vp & Basal/central/extended amygdala \\
POA & Preoptic area \\
VTn & Anterior hypothalamus \\
ATn & Ventromedial hypothalamus \\
TPp & Ventral tegmental area \\
PAG/CG & Periaqueductal gray/central gray \\
\hline
\end{tabular}

positioning of pallial nuclei that border a single ventricular cavity (along midline and surrounding outside of hemispheres) rather than paired telencephalic hemispheres surrounding an internal ventricle (Nieuwenhuys, 2011). These developmental processes place many nuclei (particularly those of the dorsal telencephalon) in different locations between teleosts and other vertebrates, making direct homologies more difficult While the SDMN represents a starting framework to study neural mechanisms of social behaviors, it is becoming increasingly clear that many other brain regions (e.g. raphe nuclei, habenula, reticular nuclei, and many others) are also involved in both receiving sensory 
inputs critical for decisions, as well as choosing behaviors that are appropriate to the social context. Based on topology, hodology, expression of receptors for sexual hormones, and functional experiments, studies in several fishes have partially defined the mammalian homologs of the SDMN in teleosts (see Table 1). These neuroanatomical homologies between fishes and tetrapods will continue to be updated as more functional and connectivity studies are performed. As we will see, functional and structural changes in these socially-relevant regions, as well as in the connectivity among them, is an important consequence of social plasticity in fish.

\section{Social organization in fish}

Fish form a unique group, being the most numerous and diverse of the vertebrates, dominating the aquatic environment by showing a remarkable panoply of behavioral characteristics and adaptations (Moyle and Cech, 2000). Fish are still erroneously viewed as primitive and inflexible, controlled by fixed behavioral predispositions; however, the reality is very different. In the last three decades, scientific evidence has somewhat repaired these misconceptions, and reintroduced fish as an "equal" group of vertebrates, rich in all sort of behaviors, even those considered as sophisticated or cognitively complex (Brown et al., 2006).

Fish occupy all aquatic niches, and their level of diversification and adaptation is remarkable. Behavioral traits maximize adaptation to the environment, giving access to food, reproductive opportunities, or social aggregation (which includes the whole social domain). The social environment of fish may have fitness consequences, as it is both a source of wellbeing as well as of conflict. In general, we may organize fish social systems into 3 categories: i) solitary, ii) individualized social units, and iii) collective social assemblages (Keenlyside, 1979, Bshary et al., 2002). Fish species living in individualized social units, may be found as pairs, harems, or in territorial neighbouring mosaics (which is the case of many fish from the pomacentrid family, a family of perciform fish from the suborder Labroidei that include damselfish and clownfish). In the case of collective social systems, these may vary in size, from smaller group units to large schools (Keenlyside, 1979). These social structures or networks may be based on distinct arrays of associations or behaviors; for instance, some are related to feeding, others to defense against predators or conspecifics, to mating, or even to cooperation (which may aggregate several of these functions) (Krause et al., 2008).

The variable functions of these social networks challenge individuals in multiple ways, with associated costs and benefits for different types of social and non-social information. The structure of each network will determine the value of each information source, thereby modulating the animals' capabilities. For example, the ability to recognize individuals within and outside the network and to gather information on relationships among group members affects the ability to make alliances, to participate in group activities, and to compete for access to food and mates (Croft et al., 2005).

There are some examples in the literature of solitary fish, including some butterflyfish, and pikes (Esox lucius and Esox masquinongy) - which are considered to be solitary and relatively sedentary carnivores showing little social interaction besides reproduction (Keenlyside, 1979). Most solitary fish studied so far are home-ranging, and not particularly territorial, but there are always exceptions (Keenleyside 1979). One interesting exception is Betta splendens, which show a marked territorial and aggressive behavior, especially in males (Simpson, 1968). Thus, even in solitary fish, social behaviors (agonistic encounters) are sometimes unavoidable.

Two marine families (Blenniidae and Pomacentridae) and one predominantly freshwater family (Salmonidae) are best representatives of fish living in territorial mosaics - that is, a system in which the home range is subdivided in a mosaic of contiguous territories (Keenlyside, 1979). The mosaic of contiguous territories occupied by these animals is a flat, two-dimensional system, with territory occupancy driven mainly by requirements of food and shelter: "Long-term utilization of benthic food can be assured by the mosaic system, each individual guarding its own resources. At the same time, thorough familiarity with escape routes and shelters within the territory reduces vulnerability to predators." (Keenlyside, 1979, p. 162). As a result, fish living in territorial mosaics have a highly fluctuating social environment as they are challenged for their territories by younger conspecifics.

Stable, long-term male-female pairs are rare among fish (Keenlyside, 1979). Some cichlid species, as those of the Cichla genus (Kullander and Ferreira, 2006), appear to form pair bonds for up to several weeks, with both parents collaborating in raising the brood until the young fish disperse (Gross and Sargent, 1985). Many species of butterflyfish (Chaetodon) have been observed to form monogamous male-female pairs for up to three years (Fricke, 1973), as well as in some species of caribbean cleaning gobies Elacatinus spp, which live and engage in cleaning together, increasing the quality of service provided to visitors (Soares et al., 2009; Côté and Soares, 2011). Interestingly, in convict cichlids (Amatitlania nigrofasciata) (Oldfield and Hofmann, 2011), Daffodil cichlid (Neolamprologus pulcher) (Reddon et al., 2015), and Chaetodontid butterflyfishes (Dewan et al., 2011), social affiliation and mating system is associated with arginine vasotocin (AVT) and isotocin (IT) (homologues of the mammalian vasopressin and oxytocin systems) neuronal systems, highlighting one of the many links between the brain and social organization.

Several species live in small groups with moderate to high complexity. In the wild, the model organism zebrafish (Danio rerio) live in small groups that form shoals, which usually include small heterospecifics (Suriyampola et al., 2015). Shoaling behavior has been exploited as a tool to study the neurobiology of social behavior in zebrafish (Soares et al., 2018a). Within the shoal, dominant-subordinate relationships are established, a model of social plasticity that has also been exploited successfully (cf. Section 5.1, below). However, many other important grouping schemes are observed across fish species that form small groups. For example, the freshwater African cichlid Neolamprologus pulcher lives on the rocky substrata of Lake Tanganyika, where it forms small groups made up of a dominant breeding pair and 0-20 smaller non-breeding subordinates called helpers (Wong and Balshine, 2011). These helpers are organized into size-based dominantsubordinate hierarchies, reflecting queues for breeding status: when the dominant female dies, helper females take its place; helper males are more likely to disperse and take over a dominant position in other groups (Wong and Balshine, 2011). Importantly, both breeders and helpers defend the territory, do maintenance work (digging and removing debris), and care for the brood (Taborsky and Limberger, 1981). This system has been used to study the neural bases of cooperative behavior (e.g., Taborsky et al., 2013; Nyman et al., 2017; Kasper et al., 2018a,b).

To navigate these complex social contexts, animals need a wide array of social skills (Soares, 2017; Soares et al., 2018a). For example, living in a territorial mosaic demands high investment in defense and competitive skills, while being a part of extended family groups will also demand defense capabilities but mostly in fine synchrony with others in the group (Bshary et al., 2002). Thus, social organization in fish take many forms, some of which exhibit complex social strategies and tactics, demands of advanced social learning capacities, elevated levels of communication, and even deception (Krause and Ruxton, 2002). Among these, cooperation and the expression of cooperative strategies among fish stands out in terms of sociality (Soares et al., 2018b). Some fish do cooperate, perhaps at lower frequencies when compared to birds and mammals (Balshine and Buston, 2008) but even so, this takes many forms: from the best-known conditional approach during predator inspection (Pitcher et al., 1986), to cooperative hunting (Bshary et al., 2006), cooperative breeding (Wong and Balshine, 2011), and finally to the notable cleaning mutualisms (Côté, 2000). Thus, the rich diversity in social organizations among fish species provides a plethora of suitable organisms to examine specific evolutionary and 
mechanistic hypotheses related to the brain and social behavior

\section{Social status and plasticity}

\subsection{Social status and plasticity of the brain and behavior}

Dominance hierarchies are an integral part of the social structure in many animal societies. As such, an individual's position or rank in the population has profound effects on their reproductive potential, access to food and other resources, overall health, and survival (Sapolsky, 2005; Wingfield and Sapolsky, 2003). Fish show diverse social societies, with examples ranging from solitary living species to group-living species that exist in either constant or ephemeral (e.g. during breeding season) hierarchies. Because of their great diversity in social, reproductive, and parental strategies, fish are powerful taxa to examine interactions between the brain and behavior. Specifically, zebrafish and cichlids are used extensively to address broad questions related to neural mechanisms of social plasticity and dominance hierarchies, and some of the main findings revealed from these species are summarized below.

Establishment of dominance hierarchies often leads to specialized social interactions and behaviors, resulting in each individual of the group occupying a specific rank in the population. This social position is constantly evaluated and reinforced by aggressive and reproductive interactions with other individuals of both higher and lower rank. In zebrafish (Danio rerio), dominant-subordinate relationships occur both between males and between females (Paull et al., 2010), and dominant males and females are more aggressive and bolder (Paull et al., 2010; Dahlbom et al., 2011). Moreover, dominance is associated with higher gonadosomatic indices and higher mRNA levels of the androgen receptor ar (in males) and estrogen receptor 1 esr (in females) in the gonads (Filby et al., 2010). These gonad differences result in a greater total reproductive success in males but not in females, but dominant females sire more offspring with the dominant male (Paull et al., 2010).

In zebrafish, much of the work on social status has been done targeting stress and arousal pathways. The establishment of a hierarchy increases cortisol levels in both dominants and subordinates, but no differences are found between dominant and subordinate fish after dominance (Pavlidis et al., 2011; Filby et al., 2010). These changes are associated with an upregulation of molecules associated with arousal (e.g., catecholaminergic, histaminergic, and orexinergic systems) in dominants, and an upregulation of the stress axis during establishment of status in subordinates that is switched to an hypocortisolemic profile when the hierarchy is established (Larson et al., 2006; Filby et al., 2010; Pavlidis et al., 2011). While 'reverse inference' should be approached with caution, it can be speculated that increased arousal is needed to patrol territories and maintain a high level of aggression in dominants, while the stress profile in subordinates is important for social plasticity of submissive behaviors.

Zebrafish also offer the opportunity to force social interactions and status transitions to discover underlying mechanisms. In one zebrafish study (Teles et al., 2016), four social phenotypes were experimentally induced: winners and losers of a real-opponent interaction; mirrorfighters, which fight their own image in a mirror and thus do not experience a change in social status despite the expression of aggressive behavior; and non-interacting fish. By analyzing the expression of plasticity genes (wnt3, neurod, npas4, bdnf, and nlgn1 and nlgn2) in regions of the SDMN, authors identified markers of social plasticity associated with social status changes: winners were characterized by greater expression of neurogenesis genes (wnt3 and neurod) in Dm, and of neuroligin genes in Vv and Vs (see Table 1 for homologies); and losers were characterized by greater expression of bdnf in $\mathrm{Dl}$ and of wnt3 in Vv, and by lower expression of nlgn2 in Vs (Teles et al., 2016). These results suggest the participation of mechanisms of neural plasticity in the establishment of social hierarchies in zebrafish.

Cichlid fish of the African (e.g. Haplochromines, Oreochromis spp.) and Neotropical (e.g. Cichlasoma spp.) clades are also ideally-suited to address questions related to the interactions between neural function and social status for several reasons. They are socially diverse, easy to manipulate, show remarkable plasticity in behavior, physiology, and brain function, and have evolved the ability to not only assess their social environment via multiple sensory channels, but also to be deceptive and determine both their own position and that of others within the hierarchy (Grosenick et al., 2007; Maruska and Fernald, 2018). Thus, cichlids display a level of social plasticity that rivals or exceeds that of many other vertebrates. In fact, they have already revealed many important discoveries about how the brain regulates and is influenced by social interactions at levels from behavior to molecular mechanisms.

There has been considerable focus on social status-specific differences in the brain of Astatotilapia burtoni (formerly Haplochromis). For example, cell proliferation (Maruska et al., 2012), neural activation in decision centers (revealed by markers such as immediate early genes), distribution, abundance, or activation of cells expressing neuromodulatory substances or their receptors (Loveland et al., 2014; Maruska et al., 2013b; O'Connell and Hofmann, 2012b; Renn et al., 2008), and aspects of the stress response system (Carpenter et al., 2014; Chen and Fernald, 2008) can all differ between dominant and subordinate males. These factors are also well known to modulate the expression of diverse social behaviors in fish as well as other vertebrates, including species like rodents and primates that are closer in phylogenetic position to humans. Similar types of social status differences are also observed in other fish species [e.g. zebrafish, as mentioned above; other cichlids, electric fish, salmonids, and others; (Gilmour et al., 2005; Maruska, 2014; Miller et al., 2017; Perrone and Silva, 2018; Teles et al., 2016)], and in some cases result in a change in an individuals' sex (male to female, or vice versa) that is accompanied by plasticity in neural circuits (Black et al., 2005; Semsar et al., 2001; Todd et al., 2018). These examples support the broad relevance of fish for addressing questions related to how an animal's social rank impacts their brain and reproductive fitness, health, and survival. Thus, by taking advantage of controlled status transitions and natural dominance hierarchies, fish have and will continue to reveal insights on neural plasticity that can inform studies in other taxa.

While much of the focus on dominance hierarchies is in males, in $A$. burtoni, establishment of dominant-subordinate hierarchies in females also induces neurotranscriptomic differences across ranks. Using cDNA microarray, Renn et al. (2016) found that several hormonal and neuropeptide genes showed higher expression in dominant compared to subordinate females, including prolactin, avt, brain aromatase, and glycoprotein alpha polypeptide subunit, a necessary precursor step in the production of active gonadotropin-releasing hormone ( $\mathrm{GnRH})$, luteinizing hormone, follicle-stimulating hormone, and thyrotropin. Interestingly, prolactin, avt, and glycoprotein alpha polypeptide subunit are also upregulated in the brains of dominant male A. burtoni (Renn et al., 2008). Neuroplasticity genes were also found to be differentially regulated by female social rank: FK506-binding protein 1, cell cycle associated protein 1, neuromodulin, and dynamin-1 were up-regulated in dominant females, while voltage-dependent $N$-type calcium channel subunit alpha-1B was expressed at higher levels in subordinate females (Renn et al., 2016). While some of these rank-specific gene expression patterns are similar between males and females, others are not. It is well established that there are differences in neural and behavioral mechanisms between males and females in many species, which highlights the importance of conducting studies in both sexes. For comparative translational science to be effective, however, increased attention must be given to sex-differences in mammals as well.

Position in a social society has profound impacts on behavior, physiology, brain function, survival, and reproductive success across vertebrates. Fishes such as zebrafish and cichlids are amenable to manipulations that control an individuals' transition in social rank, which have revealed many genes, brain nuclei, and other physiological 
correlates associated with this social plasticity. With recent advancements in genetic technologies (e.g. CRISPR, transgenics), these fish species are now poised to advance the field of social neuroscience with targeted and functional hypothesis testing to better link neural mechanisms to behavioral outcomes.

\subsection{Social status and sensory plasticity}

Studies in fish have also revealed important neural mechanisms involved in sensory plasticity. Because the ability to assess the social environment is critical, particularly for species living in dominance hierarchies, conspecific communication and sensory perception is of paramount importance. For example, social rank or alternative reproductive phenotypes (e.g. nesting vs satellite/sneaker males) within a species are often associated with differences in the ability to detect auditory, olfactory, and visual information that is necessary for their status-specific behaviors such as reproduction, territory defense, feeding, and growth. In A. burtoni, dominant males have higher levels of modulatory receptors (e.g. steroid receptors) in the ear (Maruska and Fernald, 2010b) and olfactory bulbs (Maruska and Fernald, 2010c), as well as a greater response of the olfactory epithelium to food-related odorants (Nikonov et al., 2017) compared to subordinate males. This may facilitate detection of acoustic social signals and prey/food to support their territorial status, which comes with an associated tradeoff of reduced feeding time and growth (Hofmann et al., 1999). Further, conspicuous dominant males show an increased startle response probability compared to less conspicuous subordinate males, possibly mediated by serotonin at the Mauthner neurons, that may allow them to better escape from predators (Neumeister et al., 2010; Whitaker et al., 2011). In plainfin midshipman fish, in which males are either large nesting type I or small satellite type II, there are status-dependent differences in both the vocal and auditory systems that are crucial to the reproductive fitness of this species that relies heavily on acoustic signaling (Forlano et al., 2016; Maruska and Sisneros, 2015). Sensory plasticity can be modulated both at peripheral sensory structures (i.e. ear, olfactory epithelium, retina), as well as centrally in the brain, and in most cases is controlled by plasticity in signaling of neuromodulatory molecules such as steroids, neuropeptides, and biogenic amines. Social communication in fish is often multisensory, but also depends on the reproductive strategies employed by the species, and the habitat and environmental conditions where they live, which can dictate the transmission properties and effectiveness of information sent via different sensory channels. Because modulation of sensory systems is common across vertebrates, including in humans, the diversity of sensory dependence seen in fish (i.e. species that rely on multisensory information, such as many reef fishes, vs. those relying heavily on a single sense to reproduce, such as midshipman) provides unique opportunities to uncover basic mechanisms of sensory function. The conservation of sensory structures across taxa allows research in fish to also reveal how perception of social information can be modulated by neurochemicals that change with their social rank. As mentioned above, however, sensory abilities of fishes and transmission properties of aquatic habitats can differ from those found in terrestrial organisms. Because these factors influence social behaviors, they should be considered when making comparisons across vertebrates. Nevertheless, fish are becoming valuable models to study impacts of anthropogenic noise, pollution, and climate change on sensory and brain function, opening opportunities to study the interaction of those factors with ecologically relevant sensory plasticity.

\subsection{Is the establishment of social rank inherently stressful?}

Social stressors are powerful activators of the hypothalamus-pituitaryadrenal (interrenal) axis in many species, and in rodents are even used as a model for depression (Beery and Kaufer, 2015). Initial studies on rodents increased the comprehension regarding how stressor type, timing, and other factors affect physiology and behavior (see Sgoifo et al., 1999, for a review). Studies in fishes demonstrate that an animal's social status affects its access to feeding, mates, and shelter, and different studies showed the consequences of rank-related stress to the physiology and health of dominant and subordinate individuals (Francis et al., 1993; Qvarnström and Forsgren, 1998; Valdimarsson \& Metcalfe, 2001; Iwata et al., 2008). Models for social stress in zebrafish revealed that subordinate animals show a higher brain expression of genes associated with the activation of the hypothalamus-pituitary-interrenal (HPI) axis, higher cortisol levels, peripheral expression of proinflammatory cytokines, and compromised reproductive activity immediately after hierarchy establishment (Filby et al., 2010).

Higher cortisol levels, however, are not always observed in subordinates compared to dominants, however. Pavlidis and collaborators (2011) also established a model for social rank stress in zebrafish, forcing a dyadic interaction for five days - after which dominance was successfully established. After the establishment of dominance, both subordinates and dominant males showed higher whole-trunk cortisol concentrations than control animals; no differences were observed, however, between dominant and subordinate animals. Teles et al. (2016) showed a significant increase in cortisol in winner animals (that is, animals which win a 30 min fight against a conspecific) and in animals fighting against a mirror (that is, animals which display aggression without establishing dominance), but not in loser animals.

These results suggest that, at the initiation of a social rank interaction, cortisol is more associated with aggression levels than with classical stress responses (i.e., behavioral inhibition, hypoaggressiveness, etc). However, these relationships between cortisol and stress or other behaviors like aggression are not always consistent across species. For example, the circulating cortisol levels in the cichlid A. burtoni are quite sensitive to experimental paradigms, with some studies showing higher levels in subordinate males, while others detect no differences between dominant and subordinates (Fox et al., 1997; Maruska, 2015). This illustrates a caveat of these results: cortisol levels are not very reliable as a measure of stress, especially in a comparative context. This results from the fact that the matrix in which cortisol is measured (whole body, brain, plasma), as well as timing and method of extraction, are very likely to alter the results. For example, in zebrafish cortisol is usually measured in whole-body, which, although relatively sensitive, lacks specificity. Moreover, cortisol release in the plasma is expected to produce faster physiological adjustments than, e.g., effects in the brain. As a result, it is difficult to compare data on small fish (such as zebrafish) vs. larger animals, including cichlids and trouts.

In rainbow trout subjected to stressful social interactions, dominant animals show higher aggressive behavior immediately after rank establishment, but only subordinate animals have elevated plasma cortisol levels associated with other signs of chronic stress, such as reduced feeding and reduced serotonergic activity in the brainstem (Sørensen et al., 2012). Moreover, subordinates had reduced proliferation of adult brain cells than controls, and cell proliferation was negatively correlated with the intensity of aggression received at the end of the social rank establishment (Sørensen et al., 2012). A study in the cichlid A. burtoni examined the behavioral consequences and neural activation patterns of repeated social defeat from the same aggressor and showed that individual males will switch between proactive and reactive coping behaviors over time, and each coping behavior is associated with distinct activation patterns in the brain (e.g. reactive had greater activation in raphe nuclei, while proactive had greater activation in $\mathrm{Dm}, \mathrm{Vs}$, Vc, Vd, Vp, Vv, TPp, ATn) (Butler et al., 2018).

These data in fish reaffirm the literature that was built on rodents, which show links between the neurobiology of stress and behavior, with social interactions sometimes acting as a stressor. In rodents, social stressors are used as models for depression, taking into consideration how social plasticity - including social subordination, crowding, social isolation, and social instability - influences stress responses (Beery and Kaufer, 2015). Fish are increasingly used as models for better 
understanding human mental health disorders, many of which are associated with stress responses, such as anxiety, depression, and posttraumatic stress disorder (PTSD) (see Kalueff et al., 2014; Stewart et al., 2014, 2015, for reviews discussing the possibility of using fish as models in biological psychiatry). For this translational approach to be effective and informative, studies in fish are necessary because it is important to understand the evolution and conservation of neural networks underlying the behaviours typically displayed in these neurological conditions.

\subsection{Reproductive status and plasticity}

One of the most important consequences of an individual's social status is their reproductive potential. Within a population, dominant individuals typically have an up-regulated reproductive axis and more mating opportunities compared to subordinate individuals. Studies in the African cichlid A. burtoni in particular have revealed important insights on how social rank impacts the reproductive brain [see Fernald and Maruska, 2012; Maruska, 2014; Maruska and Fernald, 2014; Maruska and Fernald, 2018, for reviews]. In this species, males form hierarchies in which a small percentage of dominant individuals hold territories that they aggressively defend from rivals and use to court and spawn with females. Subordinate males comprise the majority of the population, but lack territories and therefore have minimal chances to reproduce. Their shallow habitats along the shores of Lake Tanganyika, however, are dynamic and there are frequent opportunities for males to rise or fall in social rank, thereby switching between subordinate and dominant status. These social transitions are associated with many dramatic changes in the brain and sensory structures that allow them to better adapt to their status-specific lifestyles (see references cited above).

The brain controls both the activity of the reproductive axis, as well as the expression of behaviors and must be inherently plastic to accommodate social change. In A. burtoni, dominant males have larger gonadotropin-releasing hormone (GnRH1) neurons in the preoptic area with distinct cell and firing properties (Davis and Fernald, 1990; Ma et al., 2015; Maruska and Fernald, 2013) compared to subordinate males, which leads to increased pituitary and testes activity to promote greater reproductive potential, higher circulating sex steroids, and increased territorial and reproductive behaviors [see (Maruska and Fernald, 2013; Maruska and Fernald, 2014; Maruska and Fernald, 2018) for reviews]. When subordinate males perceive an opportunity to gain a territory and rise in social rank, within minutes, they begin looking and behaving like dominant males (Burmeister et al., 2005; Maruska and Fernald, 2010a). This social ascent is also associated with numerous rapid (minutes to days) cellular and molecular changes from the brain to the testes (Maruska and Fernald, 2014; Maruska and Fernald, 2018), and similar changes occur on a slower timescale (days to weeks) when males fall in rank (Maruska et al., 2013a; Maruska, 2015). Because changes in social position occur across invertebrate and vertebrate taxa, this rapid neural and behavioral plasticity in cichlids provides unique opportunities to test functional, mechanistic, and evolutionary hypotheses. For example, a study in haplochromine cichlids of Lake Victoria demonstrated that competition for breeding sites between males promotes male nuptial color diversification that can lead to speciation (Seehausen \& Schluter, 2004). One neuroendocrine system that links body pigmentation to fish behavior is the melanocortin system. In A. Burtoni, studies showed that yellow males are more aggressive, with higher circulating levels of 11-ketotestosterone (fishspecific androgen) than their blue counterparts (Korzan et al., 2008). However, while exogenous $\alpha$-melanocyte-stimulating hormone ( $\alpha$ $\mathrm{MSH}$ ) increases yellow coloration in both yellow and blue males, only the blue morph-type individuals increased their aggressiveness (Dijkstra et al., 2017). Thus, by combining tests of evolutionary and functional hypotheses in cichlids, we can begin to unravel the mechanisms and drivers of social plasticity.
Important work on sexual conflict and social plasticity has been done in poeciliids (see Cummings, 2018, for a review), due to the variety of reproductive strategies and levels of sexual conflict found across species. Conflict levels vary across poeciliid species mainly as a result of variation in male mating systems, given that females of most species have long gestation periods and, being able to store sperm, are rarely sperm-limited; males, on the other hand, vary from systems dominated by male coercion (about half of the species) to systems that include both courtship and coercive tactics. The result is a sex ratio that is male-biased, with the optimal mating rate for males being several times a day, while for females less than one mating episode per month is optimal. Interesting species differences are observed, with guppy (Poecilia reticulata Peter 1859) and mosquitofish (Gambusia affinis Baird \& Girard 1853) males attempting mating more than once per minute, and Panuco swordtail (Xiphophorus nigrensis Rosen 1960) males attempting mating between 0.25 and 5 times per minute (Magurran and Maciás Garcia, 2000). Thus, the relative investment in a single reproductive event varies between males and females across poeciliid species, but females always allocate more resources towards foraging and avoiding male harassment (Houde, 1997), while males allocate most of their resources towards mating attempts (Magurran and Seghers, 1994).

The resulting selective pressures described above produced species in which males and females display sexual dimorphism in social behavior and cognition (Cummings, 2018). In guppies and mosquitofish, females that experience a high degree of sexual coercion exhibited a greater tendency to shoal in the presence of male conspecifics relative to the absence of a male, while females from the $X$. hellerii or $X$. mayae do not shoal together in response to male conspecifics (Dadda, 2015). This increased aggregation in females can be interpreted as an adaptive strategy to reduce the costs of male sexual behavior. Moreover, females from species with high sexual conflict also occupy different habitats, inhabiting areas with higher predation risks to avoid male harassment (Croft et al., 2006; Darden and Croft, 2008); as a result, females from species with high sexual conflict show less exploratory behavior and increased anxiety-like behavior (Cummings, 2018). Interestingly, in $G$. affinis, a species with high sexual conflict, males that showed less neophobia and anxiety performed better on a numerosity discrimination task, whereas females showed no relationship between exploration and learning performance (Etheredge et al., 2018). No differences were found between $G$. affinis males and females in learning performance, but high-performance learner males exhibited different behavioral attributes than high-performance learner females: while high-performance females showed higher mate choice, activity, and anxiety (key responses to social conflict), high-performance males do not show higher levels of any behavioral trait (Etheredge et al., 2018).

In an interesting approach, Cummings and colleagues analyzed gene expression in whole brains or in the dorsolateral telencephalon (D1, a putative homologue of the hippocampus in teleosts) of females species with low conflict ( $X$. nigrensis) or high conflict ( $G$. affinis) that varied in levels of preference for courting vs. coercive male conspecifics (Cummings et al., 2008; Lynch et al., 2012; Wong et al., 2012; Wang et al., 2014). In X. nigrensis, the expression of neuroligin-3 and neuroserpin, genes associated with synaptic plasticity, is positively associated with preference for courting males in both the whole-brain and Dl samples; however, in G. affinis, these genes are negatively associated with preference for courting males in whole-brain samples. When $G$. affinis females are exposed to a courting heterospecific male (a large Poecilia latipinna), a positive correlation is observed between preference and neuroserpin brain levels, while a negative correlation is observed when females are exposed to a coercing P. latipinna (Cummings et al., 2008; Lynch et al., 2012; Wong et al., 2012; Wang et al., 2014). These results suggest that different expression of neuroplasticity genes across species is not due to species differences per se, but that females are responding more to male reproductive tactics than species identity. Finally, in $X$. nigrensis, females exposed to two courting males show a 

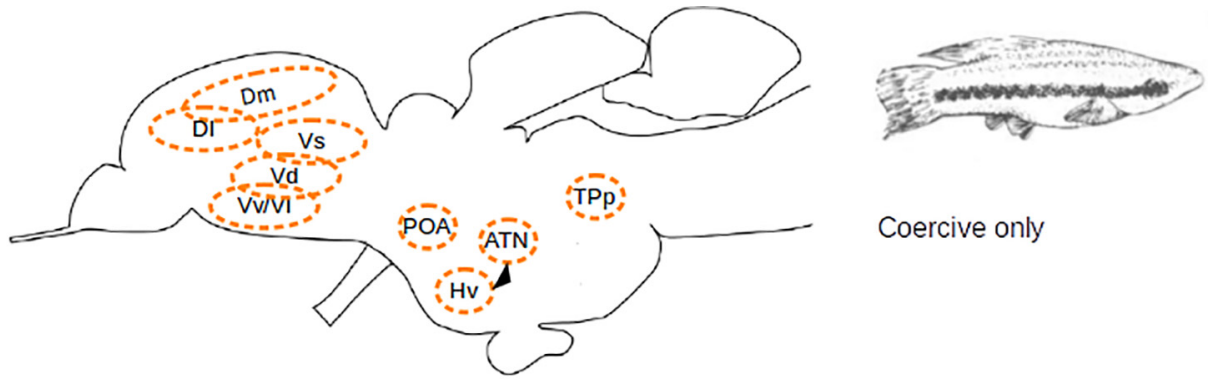

Coercive only

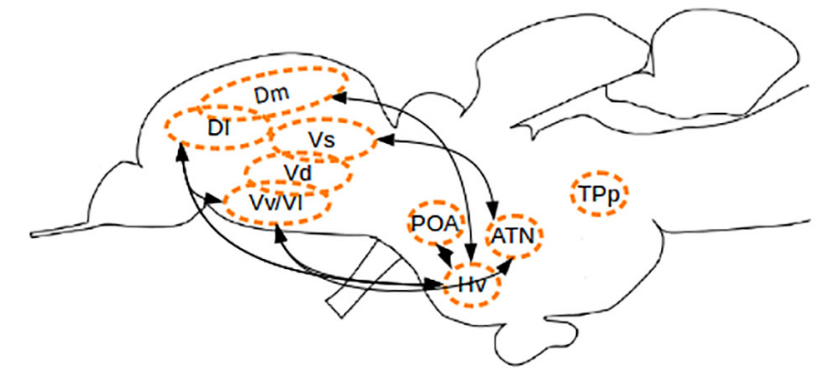

Coercive and courting

\section{Courting only}

Fig. 3. Sexual conflict and mate choice induce neuroplasticity between areas of the SDMN in female X. nigrensis. Adapted from Cummings (2018). Abbreviations: Dm - medial zone of the dorsal telencephalon; Dl - lateral zone of the dorsal telencephalon; Vs - supracommissural zone of the ventral telencephalon; Vd - dorsal zone of the ventral telencephalon; $\mathrm{Vv}$ - ventral zone of the ventral telencephalon; $\mathrm{Vl}$ - lateral zone of the ventral telencephalon; POA - preoptic area; $\mathrm{Hv}$ ventral hypothalamus; ATN - anterior tuberal nucleus; TPp - posterior tuberculum.

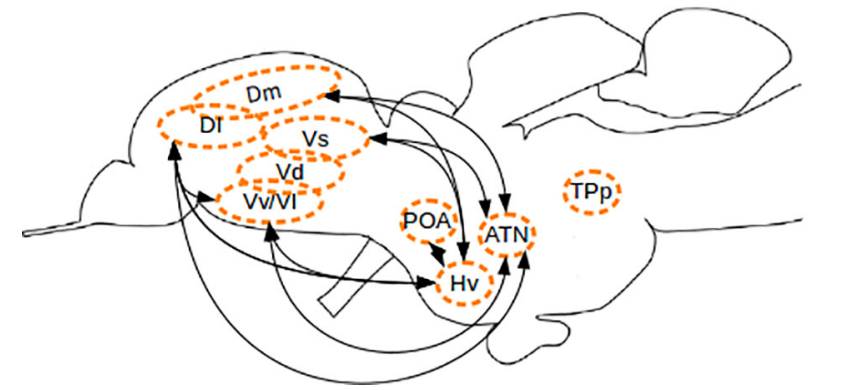

high correlation in the expression of neuroligin-3 in regions that are associated with social decision making than females exposed to a courting and a coercive male, and little correlation is observed across these regions when females are exposed to two coercive males (Wong and Cummings, 2014), suggesting that interaction with courting phenotypes, more than coercive phenotypes, demand engagement of brain plasticity (Fig. 3).

The most remarkable expression of social plasticity, however, is the sex change, an adaptive strategy that has already been observed for 27 teleost families (Sadovy de Mitcheson and Liu, 2008). Most of them are marine species, such the Epinephelidae groupers Epinephelus akaara and E. awoara, both functional protogynous hermaphrodites (Liu et al., 2016), in which individuals first function as female and then males, and in the protandrous hermaphrodites Amphiprioninae, as in Amphiprion melanopus (Choi et al., 2016) and A. ocellaris (Khoo et al., 2018), in which animals are first males and then females. Theoretically, these strategies evolved to ensure a high mating success. In protogynous hermaphrodites, for example, larger males tend to be dominant, commonly monopolizing mating, either by defending spawning sites that females visit or by controlling a harem of females. Thus, if an individual acts as a female when small and as male after achieving a large size, it would have a greater offspring in comparison to a gonochoristic (unisexual) individual (Warner, 1984). Moreover, usually a protogynous male also controls the emergence of other males by aggressive dominance over females. The former tendency was demonstrated by Lo Nostro and Guerrero (1996) in the swamp eel Synbranchus marmoratus, in which the so-called primary male, which directly develops as male, were smaller $(13 \mathrm{~cm})$, while the larger ones $(91 \mathrm{~cm})$ were found to be secondary males, which develop from functional females. Contrary to the general findings in protogynous hermaphrodite species, in which female individuals are the majority, in this study the authors showed that most of the population (80\%) was composed of secondary males. That occurrence might be a result of the survival strategy adopted by the species, since it inhabits streams and swamps that periodically dry out leaving the individual isolated. Thus, protogynous specimens are hypothetically more efficient to establish new colonies (Lo Nostro and Guerrero, 1996). The authors suggested that sex differentiation in this sex-changing species can be triggered by an initiating event in the brain, rather than directly on the gonad. Indeed, chronic administration of salmon GnRH analogue or the dopamine receptor antagonist domperidone induced sex change in female $S$. marmoratus and spermiation in males (Ravaglia et al., 1997).

Bluehead wrasses (Thalassoma bifasciatum) are dyandric protogynous labrids, presenting both smaller, drab, non-aggressive primary males, a certain percentage of which will change to a large, brightlycoloured, highly aggressive terminal male. Removal of a terminal phase male from a patch reef induces aggressive behavior in the largest female, targeted towards other females, as well as courtship towards smaller females, suggesting that one important control of sex change is dominance hierarchies (Warner and Swearer, 1991). In this species, sex change is accompanied by increases in the expression of GnRH in the POA (Grober et al., 1991), and terminal phase individuals show higher GnRH expression that intermediate phase individuals (Grober and Bass, 1991). The closely-related T. duperrey is also diandric, but females have a larger home range and do not always mate with the same male; the presence of smaller individuals promotes sex reversal and the presence of larger individuals inhibits sex reversal (Ross, 1986). In this species, norepinephrine appears to stimulate gonadal sex reversal, while dopamine exerts inhibitory action on the initiation of sex reversal and serotonin inhibits both initiation and completion of sex reversal (Larson et al., 2003a). During sex change in females, monoamine metabolism changes in the SDMN, as well as in the locus coeruleus and raphe 
nucleus (Larson et al., 2003b); during the first week of sex change, when animals undergo behavioral changes, serotonergic activity in the Dm is increased, while in the POA it is decreased (Larson et al., 2003b). Norepineprhinergic activity is decreased, and dopaminergic activity is increased, in the $\mathrm{VMH}$; in the locus coeruleus, norepinephrinergic activity is increased, while in the raphe nucleus, there is a decrease in serotonergic activity at the time of behavioral sex reversal (Larson et al., 2003b). Both studies suggest that behavioral sex reversal is under the control of serotonin in the raphe, while gonadal sex change is mediated by serotonergic effects on norepinephrine in the POA. In addition to sex-change, there are numerous other examples of alternative reproductive phenotypes across fish species, all showing plasticity in behavior, the brain, and physiology that can be useful for revealing core neural mechanisms across taxa (for reviews see Maruska et al., 2018; Oliveira et al., 2008).

\section{Cognitive plasticity and social interactions}

By definition, cognitive social plasticity refers to the ability to change patterns of cognition and behavior in the context of social engagement. This field, as with many others, was initially developed to tackle "human questions", as part of social psychology, and later applied to other vertebrates including fish. Indeed, the diversity of fish species, social systems and cognitive abilities, together with the variety of adaptive contexts in which these species evolved, stirred the interest to generate new behavioral and cognitive paradigms with higher ecological validity (Hall et al., 2014). Recently, the use of fish in neurosciences, mostly zebrafish, and the development of new molecular tools, has created new possibilities and consequently, taken many more model fish species into the spotlight. However, when thinking about social behavior and cognition, not many fish species or families come to mind, except for a few well studied examples as the cichlids (Grosenick et al., 2007; Greenwood et al., 2008; Oldfield and Hofmann, 2011; Winberg et al., 2008) and the cleaner wrasses (Bshary and Côté, 2008; Soares 2017); with a few others coming as runner-up candidates, such as zebrafish (Oliveira, 2013), poeciliids (Dugatkin, 1988, 1991), or cleaning gobies (Côté and Soares, 2011).

In this section, we will focus on the cleanerfish example, as it is possibly the best studied fish system in terms of complex social behavior and includes both interspecific and conspecific components (Soares, 2017). Cleaners are suitable candidates as model organisms to study the role of social plasticity in contextual social cognition and decision making; moreover, they are also putative models for more "organizational" questions, as those focusing on the evolutionary emergence of cleaning behavior (between species, Soares et al., 2018a), ontogenetic changes in cleaning behavior (the case of facultative cleaners, Soares et al., 2018a), and of alternative strategies (adaptive behavioral ecotypes, as with the Caribbean cleaning goby Elacatinus prochilos) (Côté and Soares, 2011). Neuroendocrine trade-offs are assumed to play a crucial role on cleaners' highly plastic social performance, enabling a successful navigation within and across challenges posed by the social environment (Soares, 2017; Soares et al., 2018a,b). Recent research, while still just begining, has provided us with a few good potential candidates regarding the proximate mechanisms, such as the nonapeptides AVT and IT, the stress steroid cortisol, and the monoamines dopamine and serotonin.

\subsection{Social plasticity and the special case of the cleaner fish system}

Fish, as other vertebrates, need to use previously acquired information and combine it with the current social environment, if they are to avoid putative costs. For instance, these include being eaten by a predator while inspecting it, or being expelled from the social group (Oliveira, 2009). According to Oliveira (2009), the ability to appropriately adjust social behavior relies on social plasticity mechanisms that occur in different temporal scales: the first is associated with changes to life-history, with those being reversible (breeding vs nonbreeding) or irreversible (juvenile cleaners vs adult non-cleaners); the second occurs during the same life-history stage, described as punctual or short term behavioral fluctuations (behavioral flexibility). Here, we prefer to envision these categories in a non-fixed manner, using them to virtually differentiate the multiple domains of social plasticity, some working between irreversible life stages, others seasonally, and some punctually; the first two being mostly modulated by non-social factors (like diet, reproduction), and the latter by contextual changes of the social environment.

Fish are remarkable examples of social plasticity and behavioral flexibility. A notable case of a highly social and cooperative species, the indo-pacific bluestreak cleaner wrasse Labroides dimidiatus, has been exploited as a model for sociality and cooperation. Individuals of this species are known to exhibit complex cognitive skills, such as predisposition to approach partners, impulsivity and deception, social recognition and inference, learning and memory, communication and levels of investment, and bonding (Soares, 2017). These skills make them good examples of strategic sophistication in decision making in teleosts, which ultimately translates into a unique demonstration of fish social plasticity (Bshary, 2001, Bshary and Côté, 2008, Soares, 2017). Naturally, the cleaning system has developed strong interest, since the very idea that fish could repeatedly move away from all their activities just to visit a specific and territorial, smaller and colourful other species, is still puzzling (Côté, 2000).

The discovery of conflict in what seemed as harmless ectoparasite gleaning behavior, was a massive step forward in understanding the social complexity of this system: Grutter and Bshary (2003) showed that these cleaners, while foraging on ectoparasites, preferred to feed directly on client mucus, which is energetically costly for the client fish to produce and constitutes cheating. In our view, this was the starting point that enabled the accumulation of evidence on the social and cooperative building blocks of this system. Cleaners and clients are involved in a challenging network of interactions, based on behavioral and physiological costs and benefits (Soares, 2017). Clients were discovered to make use of partner control mechanisms aiming to reduce the frequency of cheating events; these mechanisms include close monitoring of cleaner behavior, for instance, in choosing beforehand (eavesdropping) and reacting with termination, switching to other cleaners, or retaliating when bites occur during the cleaning (Bshary and Côté, 2008). Thus, clients not only gain from successful parasite removal, but also with a whole neuroendocrine cascade of wellbeing derived from physical and visual contact (Ros et al., 2011; Soares et al., 2011, 2017a; Abreu et al., 2018a,b,c). As a dynamic biological "market", cleaners are challenged to respond in flexible way, changes that may occur in relation to clients' species and identity (familiarity previous recognition, Tebbich et al., 2002, Soares et al., 2017b); these cognitive modules and physiological mechanisms will be further discussed below.

Adding to all this behavioral plasticity, most cleaner species undergo seasonal variations, mostly related to reproduction, which have significant dietary physiological impact (Soares et al., 2014), and hence impact on cleaners' cooperative levels (Bshary, 2002). Temperature and other environmental fluctuations also influence cleaners' social plasticity, especially when these tend to be extreme. This was firstly documented in a recent study by Triki and colleagues (2018), which found that, following the extreme weather events affecting the Great Barrier Reef (consecutive cyclones and the 2016 El Nino event), cleaners failed to display the previously documented strategic abilities (lower ability to manage their reputation and to learn to prioritize food sources as to maximize food intake). These changes were mostly due to a change in clientele densities, which means that the contextual social environment is crucial to the development of cleaners high-end social and interspecific abilities, cognitive differences that had been previously noted by Wismer et al. (2014) in cleaner wrasses from different reefs, and in other species of dedicated (full time) cleaners (the Caribbean cleaning 
gobies Elacatinus spp., Soares et al., 2008).

It's also relevant to note that cleaners are found in many different fish families and most of which only do so in a specific life stage (during the juvenile phase; Côté, 2000, Vaughan et al., 2016). These transitions are of significant social relevance, as these facultative cleaner species stop interacting with heterospecifics to focus exclusively on their conspecific networks (frequently during adulthood). Finally, some species of cleaning gobies (most notably the case of Elacatinus prochilus, Côté and Soares, 2011) show alternative mixed strategies, which seem to adaptably express cleaning behavior, with the absence of cleaning being associated with the sponge-dwelling habitat and the presence of cleaning associated with living on substrata other than sponge (Rüber et al., 2003; Taylor and Hellberg, 2005). Whether this is exclusive to Elacatinus spp cleaning gobies or something observed in certain socioenvironmental conditions or species, is yet to be discovered. But even in systems other than $L$. dimidiatus, variations of behavioral output are cumulatively being documented: for instance, with the effects of competition in cleaning gobies (Soares et al., 2008), or the effects of uneven habitat use to cleaner-client familiarity and to cleaners' cheating levels (Oates et al., 2010). At this point much have been done in terms of behavior, ecology, and physiology of cooperative behavior in cleaner fish, however, the cleaner-client mutualism is still a promising system, most especially in matters of social plasticity and the underlying brain mechanisms.

\subsection{Nonapeptides in social plasticity of cleaner fish}

The nonapeptides, arginine-vasotocin (AVT) and isotocin (IT), have a well-conserved structure and core functions across vertebrate taxa (Acher and Chauvet, 1995; Goodson and Bass, 2001), and are implicated in great number of social and reproductive behaviors in fishes (Godwin and Thompson, 2012). In teleosts, AVT and IT-immunoreactive (ir) neurons of the preoptic area (POA) are the main source of these nonapeptides, have neuronal projections both to the pituitary and to extrahypothalamic brain regions, which include the diencephalon, telencephalon, optic tectum cerebellum and brain stem (Holmqvist and Ekström, 1995; Saito et al., 2004). A comparative study found that obligate cleaners $L$. dimidiatus have smaller and less numerous AVT-ir neurons in the gigantocellular preoptic area (gPOA) compared to non-cleaners, the corallivorous Labrichthys unilineatus (Mendonça et al., 2013). As such, differences in bio-active AVT and IT quantitative levels are expected to occur selectively, in accordance to species, social behaviour and brain regions involved, as we will further develop bellow.

Arginine-Vasotocin has been found to have tremendous effects on the cleaning predisposition of cleaner wrasses. Intramuscular injection of AVT made cleaners cease inspecting clients and instead turned their focus to conspecific activities, while those injected with V1a receptor antagonists were stimulated to clean (Soares et al., 2012a). Similar learning and cooperative deficits were subsequently found after exogenous AVT injections (Cardoso et al., 2015a,b). AVT appears to work as a switch, turning "on" or "off" the expression of interspecific cooperative behavior of cleaner wrasses, indicating that lower levels of AVT could be a prerequisite for approaching and interacting with clients while higher AVT activity could predispose cleaners into mating activities (Cardoso et al., 2015a). Interestingly, examination of brain active nonapeptide levels of mixed sex pairs of cleaner wrasse L. dimidiatus demonstrated that in males, forebrain isotocin (IT) levels increased with the level of pair association, but no relationship was found for females (Fig. 4B; Cardoso et al., 2015c). These males were found to receive more tactile stimulation from female partners, but seem to contribute to an overall decrease of cleaning service quality given to clients (i.e. cheated more often; Cardoso et al., 2015c). Recently, male cleaner forebrain IT levels have been found to increase when introduced to clients (visual-only or full contact), compared to conspecifics (Abreu et al., 2018b; Fig. 5).
This evidence pointed towards the need for comparative studies. Kulczykowska et al. (2015) looked at biologically available nonapeptide levels (measured via liquid chromatography-tandem mass spectrometry) in different brain regions of four species of closely related Labrid fish, and found that in the cerebellum of the obligate cleaners $L$. dimidiatus and L. bicolor, AVT and IT levels were higher than those of facultative cleaner $L$. australis (in which juveniles are cleaners and adults are corallivorous) and of a non-cleaner species L. unilineatus, suggesting that AVT levels at the cerebellum may be associated with the expression of cleaning behavior (Fig. 4A). Thus at this point, it's safe to say that the nonapeptides AVT and IT are implicated in decisionmaking in cleaner wrasse, but with AVT strongly mediating structural and perhaps life-history changes between cleaning and non-cleaning, however much is yet to be discovered.

\subsection{Cortisol in social plasticity in cleaner fish}

Cortisol was described as a strong candidate modulator of cleaners and clients' behavioral decisions (Soares et al., 2014; Binning et al., 2017; Soares, 2017). The involvement of cortisol was more obvious in clients, as these visit cleaners to have their parasites removed, and these parasites may cause discomfort, itching, disease, and immune dysfunctions (Côté, 2000). On the other hand, for cleaners, cortisol should have a role as a mediator of stress and antipredator responses, since some clients are dangerous piscivores, which cleaners graze around and inside their mouths and leave unharmed (Soares et al., 2007). Interaction of cleaners and clients increase cortisol levels in the first, causing them to attend these clients faster and during longer bouts of time (Soares et al., 2007, 2012b). Indeed, it has been hypothesized that variations in cortisol levels work to "fine-tune" cleaners' behavioral profiles by contributing to behavioral shifts (Soares, 2017).

Bshary (2002) proposed a description of two non-fixed cleaner behavioral strategies: the first is adopted by the great majority of cleaners, which show low interest in small clients and focus on the best treatment of larger clients, and the second - known as "biting", in which cleaners behave in the opposite manner and bite ("cheat") the larger and most valuable non-predatory clients. Cortisol plays a decisive role in these behavioral shifts, which occur in stages of higher metabolic demands (and as a consequence, increased glucocorticoid expenditure), such as during stages of high reproductive effort, high growth effort, or during stages of change in female social rank (see Soares et al., 2014). However, the scope of influence by cortisol variations seems to be set by the social environment inhabited by cleaners. For instance, only cleaner wrasses inhabiting highly complex social environments seem to respond to exogenous cortisol injections with strategy shifts (e.g. tactical deception of clients: more tactile stimulation to small clients and more bites to large clients; Binning et al., 2017). Another good example is the case of ecotype differences in cleaning gobies (Soares et al., 2011), as the absence of cleaning is related to sponge-dwelling habitat and the presence of cleaning is associated with living on substrata rather than sponge (Rüber et al., 2003; Taylor and Hellberg, 2005). Stress mechanisms are involved in this system, with species that show both cleaner and non-cleaner strategies (E. prochilos) responding more to stressful events and in this way enabling the necessary robustness that allows for them to develop in one of these social environments: one more hierarchical and aggressive (sponges), and another more tolerant and riskier (substratum) (White et al., 2007; Soares et al., 2018a). There is also a high degree of behavioral flexibility; for instance, sponge dwellers have been observed to inspect clients (Côté and Soares, 2011). However, species of cleaning gobies that are specialized in cleaning (such as E. evelynae), depending exclusively on the client-derived food and inspecting dangerous clients often, seem to depend on more precise cortisol responses that enable them to react to smaller trophic differences between clients (Soares et al., 2012b; Soares et al., 2018a). These results suggest that cortisol work to "fine-tune" cleaners' behavioral profiles by contributing to behavioral shifts and flexibility. 


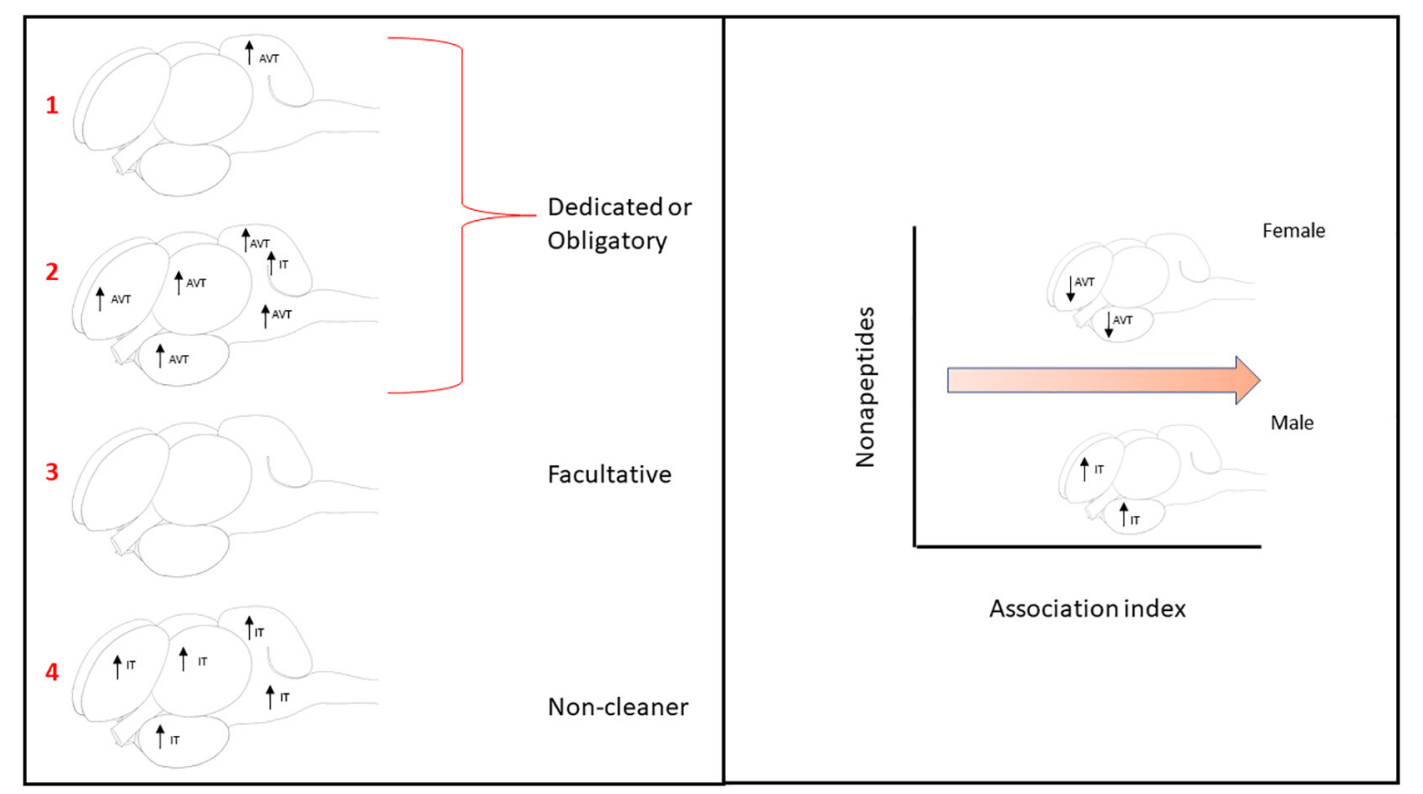

Fig. 4. Role of brain nonapeptides arginine-vasotocin (AVT) and isotocin (IT) in mutualism in cleanerfish. (A) Differences in nonapeptide levels between closelyrelated cleanerfish species: 1 and 2) obligatory cleaners Labroides dimidiatus and Labroides bicolor; 3) facultative cleaner Labropsis australis and 4) non-cleaner species, Labrichthys unilineatus (adapted from Kulczykowska et al., 2015). (B) Differences between male and female Labroides dimidiatus couples, in accordance to their association index - proportion of time spent cleaning together (adapted from Cardoso et al., 2015a,b,c,d).

\subsection{Monoamines in social plasticity in cleaner fish}

Cognitive function in cleaner fish (and other teleosts) requires flexible coordination of multiple specialized areas of the brain; some of these regions are part of the SDMN. A participation of monoamines in learning and cognition has already been demonstrated in $L$. dimidiatus, as dopamine D1 receptor agonists improves learning of both a cue discrimination task and a side discrimination task (Messias et al., 2016), while serotonin $1 \mathrm{~A}$ receptor antagonists delays learning of a cue discrimination task (Soares et al., 2016). Recently, efforts have been made to understand how the main brain areas respond, in terms of serotonergic and dopaminergic signalling, during the processing of complex social and mutualistic information (Abreu et al., 2018c; Maximino et al., 2018 [https://doi.org/10.1101/326843]). Abreu et al. (2018c) demonstrated that diencephalon serotonergic activity is particularly responsive in a situation of visual stimulation even in absence of actual physical contact (Fig. 5), suggesting that this region processes the cleaner's intrinsic motivation to interact regardless of the outcome

\section{A Non-social}

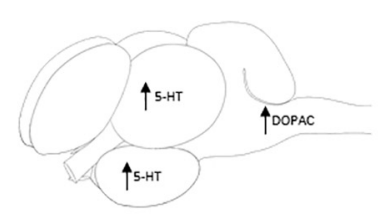

B1 Conspecific
(visual + physical)

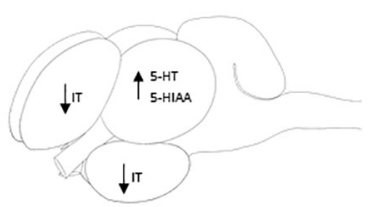

C1 interspecific (visual + physical)

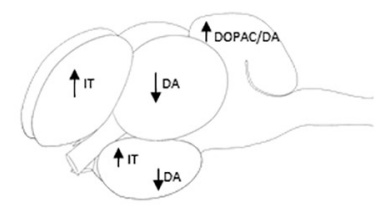

B2 Conspecific

(visual)

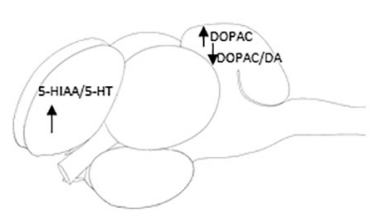

C2 interspecific (visual)

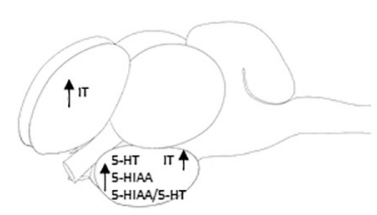

Fig. 5. Cleaner brains presents different neuroendocrine shifts that are related to contextual treatments at 3 levels: A) non-social, B1 and B2) conspecific, and C1 and C2) interspecific. At different macro-areas: forebrain, diencephalon, optic tectum, cerebellum, and brainstem. Experimental setup, individual cleaner Labroides dimidiatus exposed to A) a ball, B) another conspecific, and C) a client. Abreviations: Dopamine (DA) and Serotonin (5-HT; 5-hydroxytryptamine), 3,4-dihydroxyphenylacetic acid (DOPAC), 5-hydroxy indole acetic acid (5-HIAA), isotocin (IT). (Adapted from Abreu et al., 2018a,b). 
(but see Paula et al., 2015). While the decrease of dopaminergic activation was expected in the case of social reward omission, this was seemingly only observed when cleaners were prevented to interact with novel conspecifics rather than clients (Fig. 5). The importance of cleaners' conspecific relationships, the value of couple dynamics to the overall expression of a series of "bilateral" behaviors between pair partners (conspecifics) and clients, and how these are modulated by cleaners' brain mechanisms, leaves plenty to look forward to in future studies. Interestingly, it was the actual cleaning engagement that resulted in significant change of dopaminergic activity, this time at the cerebellum (Abreu et al., 2018c; Fig. 5). As is the case with reproductive plasticity and choice in poeciliids, then, the cerebellum appears as a main area for processing mutualistic information (Kulczykowska et al., 2015), as it is strongly implicated in cognitive and emotional functions, namely in those linked to associative learning and memory processes.

\subsection{Social plasticity and brain size in guppies}

The association of plasticity-related molecules and social plasticity is also of interest because it raises the question of whether brain morphology is altered by different social contexts, since many of these molecules are also involved in early brain differentiation, brain size, and gross morphology. Interesting studies have been developed in the guppy $P$. reticulata to investigate whether general and specific brain morphology is associated with navigating complex social environments. A relationship between social plasticity and brain size was found by Kotrschal et al. (2012), who observed that male brains were larger in guppies that interacted with females, while the optic tectum was larger in females in female-only groups, suggesting that, while differences in brain sizes between sexes can be attributed to differences in emotional and foraging behavior, cognitive demands associated with courtship can also be responsible for brain size plasticity. Similar changes are seem after multiple generations of breeding guppies for large and small brain size relative to body size: after only two generations of selection, Corral-López et al. (2018) found that non-selected and large-brained males, but not small-brained males, showed context-dependent preferences for larger females that depend on the difference in female size; similarly non-selected and large-brained females show a strong preference for males with color traits that predict attractiveness in $P$. reticulata (Corral-López et al., 2017). That social complexity changes brain size has also been observed in the cooperatively breeding cichlid $N$. pulcher, in which the size of the rearing group influences both the development of aggressive and submissive behavior and the size of the optic tectum, hypothalamus, and cerebellum (Fischer et al., 2015). Finally, social competence is also associated with brain size, with dominance being established earlier in contests with losers which were selected for large brain size, whereas the brain size of the winner had no effect (van der Bijl et al., 2018).

\section{Conclusions}

Social plasticity represents a challenging, yet evolutionarily and translationally relevant field of investigation across species. The overreliance on a few "choice species", under the assumption that they more closely model the human organism, not only does not make evolutionary sense, but also risks missing translationally relevant mechanisms (Gerlai, 2014) of social plasticity. The wide range of social organizations across fish species makes them ideal model organisms to study the relationship between social plasticity and brain plasticity.

Patterns of modulation emerge when species and situations are compared. For example, a role for nonapeptides is observed during the establishment of dominance hierarchies; given the relationships between AVT and aggression in fish, this is not surprising, as behavioral shifts towards more aggressive phenotypes are advantageous when establishing dominance. A limitation of using fish, in this sense, is that brain contents cannot typically be analyzed without killing the animal, and therefore it is not yet possible to know whether nonapeptide levels are already high before the establishment of hierarchies (and therefore predict dominance), or whether they increase to shift behavior. Interestingly, however, in the Indo-Pacific cleaner wrasses nonapeptides are implicated in decision-making, with AVT acting as an ontogenetic and punctual switch between cleaning and non-cleaning; since cleaning is not expected to involve aggression, these results underline the role of nonapeptides not only on aggression-based social dynamics, but also on cooperation and mutualism.

Monoamines are also implicated in neural plasticity, especially in the contexts of motivation, arousal, and emotional behavior (Forlano and Bass, 2011). Serotonin is a "pleiotropic" neurotransmitter, being involved in aggression, antipredator defense, fear and anxiety, and social behavior (Herculano and Maximino, 2014). In fish, changes in the serotonergic system were associated with behavioral sex reversal, with serotonin mediating decreased aggression and dominance. Social status changes also mediate sensory plasticity by modulating the serotonergic system, and diencephalic serotonin is important for the establishment of interspecific cooperation in cleaner wrasses. Thus, social plasticity of the serotonergic system appears to be important to induce behavioral shifts associated with aggression and antipredator behavior. Also, the raphe nucleus which contains serotonergic neurons was implicated in regulating reactive coping behaviors associated with repeated social defeat in an African cichlid (Butler et al., 2018). Peptides and monoamines, as well as cortisol, appear to act as "initiators" of brain plasticity in a context of social plasticity.

Not surprisingly, changing social status, reproduction, or behavioral strategy warrants structural and functional changes in the SDMN. The work reviewed here showed that markers of neuroplasticity and cell proliferation are stimulated by social status changes, as well as by reproductive status changes (including sex reversal and mate choice). Interestingly, these effects appear to be restricted to dominants, in the case of social status. Whether the absence of effects in subordinates results from technical limitations (e.g., lack of sensitivity), stress effects (which can impair memory, for example), or other reason is still unknown. However, the breadth of species and contexts in which these plastic changes take place points to these molecules as "core" mechanisms in consolidating brain plasticity in a context of social plasticity.

The work discussed here also underlines potentialities and limitations of the SDMN approach. Not surprisingly, social plasticity appears to be associated with neural plasticity across regions of the SDMN; thus, in principle, focusing on these regions can improve the power of comparative research to find conserved mechanisms of social plasticity across species and social contexts, as well as to help in the discovery of context-specific changes. Focusing on the role of specific neurotransmitters and neuromodulators (e.g., monoamines and nonapeptides) on these changes seems to be the obvious way forward. At the same time, changes are also observed in areas not usually associated with the SDMN, including the cerebellum, optic tectum, and regions of the hindbrain associated with escape responses and prey capture. This suggest that a too narrow focus on the SDMN can create blind spots, as other regions involved in social plasticity and context-dependent behaviors are ignored.

Fish are also valuable for understanding the neural substrates and circuitry that govern social behaviors, particularly in an evolutionary context. While the SDMN provides a useful framework for investigating brain regions involved in social plasticity, many other brain nuclei are implicated in context-dependent behaviors that should also be considered. The everted teleost telencephalon also limits translation of fish studies to other vertebrates until the homologies are better established. Nevertheless, it appears as though some brain regions (and neural circuits) are common to broad behavioral contexts like the POA in reproduction and the ATn (homolog of ventromedial hypothalamus) in aggression, but how these circuits were co-opted for distinct behaviors in different species remains an intriguing question. 
Overall, fish represent an under-studied but promising taxon in the field of social plasticity. In addition to zebrafish, which have been introduced in the neuroscience literature, many other species are associated with vibrant research communities, important "base" knowledge to ground neurobehavioral studies on neuroethology, and species-specific social organizations which beget the need to understand commonalities and differences in terms of social plasticity in the brain. The future awaits more neuroscientists working with these animals to increase both evolutionary neuroscience and translational studies.

\section{Acknowledgments}

KPM acknowledges support from the National Science Foundation (IOS-1456004; IOS-1456558). MCS is currently supported by SFRH/ BPD/109433/2015 (research focusing on cleanerfish financed by the Foundation for Science and Technology-FCT, grant PTDC/MAR/ $105276 / 2008$ given to MCS). MLM is a recipient of a CNPq grant (Edital Universal 2016; Processo 423735/2016). CM is the recipient of a CNPq grant (Edital Universtal 2016; 400726/2016-5).

\section{References}

Abreu, M.S., Kulczykowska, E., Cardoso, S.C., André, I.G., Morais, M., Gozdowska, M., Soares, M.C., 2018a. Nonapeptide levels in cleaner fish brain during interactions with unfamiliar intra and interspecific partners. Behav. Ecol. Sociobiol. 72, 122.

Abreu, M.S., Messias, J.P.M., Thörnqvist, P.O., Winberg, S., Soares, M.C., 2018b. Monoaminergic changes at the forebrain and diencephalon signal the occurrence of mutualistic and conspecific trade-offs in fish. Sci. Rep. 8, 7346.

Abreu, M.S., Messias, J.P.M., Thörnqvist, P.O., Winberg, S., Soares, M.C., 2018c. The variable monoaminergic outcomes of cleaner fish' brains when facing different social and mutualistic contexts. PeerJ 6, e4830.

Acher, R., Chauvet, J., 1995. The neurohypophysial endocrine regulatory cascade: precursors, mediators, receptors, and effectors. Front. Neuroendocrinol. 16, 237-289. https://doi.org/10.1006/frne.1995.1009.

Ashur, M.M., Johnston, N.K., Dixson, D.L., 2017. Impacts of ocean acidification on sensory function in marine organisms. Integr. Comp. Biol. 57, 63-80.

Balshine, S., Buston, P.M., 2008. Cooperative behaviour in fishes. In: Magnhagen, C, Braithwaite, V.A., Forsgren, E., Kapoor, B.G. (Eds.), Fish Behaviour. CRC Press/ Taylor \& Francis, Boca Raton, FL, pp. 437-484.

Beery, A.K., Kaufer, D., 2015. Stress, social behavior, and resilience: Insights from rodents. Neurobiol. Stress 1, 116-127.

Binning, S.A., Rey, O., Wismer, S., Triki, Z., Glauser, G., Soares, M.C., Bshary, R., 2017. Reputation management promotes strategic adjustment of service quality in cleaner wrasse. Sci. Rep. 7, 8425. https://doi.org/10.1038/s41598-017-07128-5.

Black, M.P., et al., 2005. Socially induced and rapid increases in aggression are inversely related to brain aromatase activity in a sex-changing fish, Lythrypnus dalli. Proc. Biol. Sci. 272, 2435-2440.

Braun, C.B., 2015. Signals and noise in the octavolateralis systems: what is the impact of human activities on fish sensory function? Integr. Biol. 10, 4-14.

Brown, C., Laland, K., Krause, J., 2006. Fish cognition and behaviour. In: Brown, Culum, Laland, Kevin (Eds.), Jens. Blackwell Publishing, Krause.

Bshary, R., 2001. The cleaner fish market. In: Noë, R., van Hooff, J.A.R.A.M., Hammerstein, P. (Eds.), Economics in Nature. Cambridge Univ. Press, Cambridge, pp. $146-172$.

Bshary, R., 2002. Building up relationships in asymmetric co-operation games between the cleaner wrasse Labroides dimidiatus and client reef fish. Behav. Ecol. Sociobiol. 52, 365-371. https://doi.org/10.1007/s00265-002-0527-6.

Bshary, R., Côté, I.M., 2008. New perspectives on marine cleaning mutualism. In: Magnhagen, C., Braithwaite, V.A., Forsgren, E., Kapoor, B.G. (Eds.), Fish Behaviour. Science Publishers, New Hampshire, NH, pp. 563-592.

Bshary, R., Wickler, W., Fricke, H., 2002. Fish cognition: a primate eye's view. Anim. Cogn. 5, 1-13.

Bshary, R., Hohner, A., Ait-el-Djoudi, K., Fricke, H., 2006. Interspecific Communicative and Coordinated Hunting between Groupers and Giant Moray Eels in the Red Sea. PLoS Biol. 4, e431.

Burmeister, S.S., Jarvis, E.D., Fernald, R.D., 2005. Rapid behavioral and genomic responses to social opportunity. PLoS Biol. 3, e363.

Butler, J.M., Whitlow, S.M., Roberts, D.A., Maruska, K.P., 2018. Neural and behavioral correlates of repeated social defeat. Sci. Rep. 8, 6818.

Cardoso, S.C., Bshary, R., Mazzei, R., Paitio, J., Oliveira, R., Soares, M.C., 2015b. Arginine vasotocin modulates learning in the mutualistic cleanerfish Labroides dimidiatus. Behav. Ecol. Sociobiol. 69, 1173-1181.

Cardoso, S.C., Paitio, J.R., Oliveira, R.F., Bshary, R., Soares, M.C., 2015c. Arginine vasotocin reduces levels of cooperative behaviour in a cleaner fish. Physiol. Behav. 139, 314-320.

Cardoso, S.C., Paula, J.R., André, G.I., Messias, J.P., Gozdowska, M., Kulczykowska, E., Soares, M.C., 2015d. Forebrain neuropeptide regulation of pair association and behavior in cooperating cleaner fish. Physiol. Behav. 145, 1-7.

Cardoso, S.A., Teles, M.C., Oliveira, R.F., 2015a. Neurogenomic mechanisms of social plasticity. J. Exp. Biol. 218, 140-149.

Carpenter, R.E., et al, 2014. Social opportunity rapidly regulates expression of CRF and CRF receptors in the brain during social ascent of a teleost fish, Astatotilapia burtoni. PLoS One 9, e96632.

Chen, C.C., Fernald, R.D., 2008. Sequences, expression patterns and regulation of the corticotropin-releasing factor system in a teleost. Gen. Comp. Endocrinol. 157, $148-155$.

Choi, Y.J., Habibi, H.R., Choi, C.Y., 2016. Profiles of gonadotropin-inhibitory hormone and melatonin during the sex change and maturation of cinnamon clownfish, Amphiprion melanopus. Biochem. Biophys. Res. Commun. 475, 189-193. https:// doi.org/10.1016/j.bbrc. 2016.05.073.

Cline, H.T., 2001. Dendritic arbor development and synaptogenesis. Curr. Opin. Neurobiol. 11, 118-126.

Corral-López, A., Bloch, N.I., Kotrschal, A., van der Bijl, W., Buechel, S.D., Mank, J.E., Kolm, N., 2017. Female brain size affects the assessment of male attractiveness during mate choice. Sci. Adv. 3, e1601990.

Corral-López, A., Kotrschal, A., Kolm, N., 2018. Selection for relative brain size affects context-dependent male preferences, but not discrimination, of female body size in guppies. J. Exp. Biol.

Côté, I.M., 2000. Evolution and ecology of cleaning symbioses in the sea. Oceanogr. Mar. Biol. 38, 311-355.

Côté, I.M., Soares, M.C., 2011. Gobies as cleaners. In: Patzner, R.A., Van Tassell, J.L., Kovacic, M., Kapoor, B.G. (Eds.), The Biology of Gobies. Science Publishers Inc.

Croft, D.P., James, R., Ward, A.J.W., Botham, M.S., Mawdsley, D., Krause, J., 2005 Assortative interactions and social networks in fish. Oecologia 143, 211-219.

Croft, D.P., Morrell, L.J., Wade, A.S., Piyapong, C., Ioannou, C.C., Dyer, J.R.G., Champman, B.B., Yan, W., Krause, J., 2006. Predation risk as a driving force for sexual segregation: a cross-population comparison. Am. Nat. 167, 867-878.

Cummings, M., 2018. Sexual conflict and sexually dimorphic cognition-reviewing their relationship in poeciliid fishes. Behav. Biol. Sociobiol. 72, 73.

Cummings, M.E., Larkins-Ford, J., Reilly, C.R.L., Wong, R.Y., Ramsey, M.E., Hofmann, H.A., 2008. Sexual and social stimuli elicit rapid and contrasting genomic responses. Proc. R. Soc. Lond. B 275, 393-402.

Curley, J.P., Jensen, C.L., Mashoodh, R., Champagne, F.A., 2011. Social influences on neurobiology and behavior: epigenetic effects during development. Psychoneuroendocrinol 36, 352-371.

Dadda, M., 2015. Female social response to male sexual harassment in poeciliid fish: a comparison of six species. Front. Psychol. 6, 1453.

Dahlbom, S.J., Lagman, D., Lundstedt-Enkel, K., Sundström, L.F., Winberg, S., 2011 Boldness Predicts Social Status in Zebrafish (Danio rerio). PLoS One 6, e23565.

Darden, S.K., Croft, D.P., 2008. Male harassment drives females to alter habitat use and leads to segregation of the sexes. Biol. Lett. 4, 449-451.

Davis, M.R., Fernald, R.D., 1990. Social control of neuronal soma size. J. Neurobiol. 21, 1180-1188.

Dijkstra, P.D., Maguire, S.M., Harris, R.M., Rodriguez, A.A., DeAngelis, R.S., Flores, S.A., Hofmann, H.A., 2017. The melanocortin system regulates body pigmentation and social behaviour in a colour polymorphic cichlid fish. Proc. R. Soc. B Biol. Sci. 284, 20162838. https://doi.org/10.1098/rspb.2016.2838.

Dugatkin, L.A., 1988. Do guppies play TIT FOR TAT during predator inspection visits? Behav. Ecol. Sociobiol. 23, 395-399. https://doi.org/10.1007/BF00303714.

Dugatkin, L.A., 1991. Dynamics of the TIT FOR TAT strategy during predator inspection in the guppy (Poecilia reticulata). Behav. Ecol. Sociobiol. 29, 127-132. https://doi. org/10.1007/BF00166487.

Dunlap, K.D., Chung, M., Castellano, J.F., 2013. Influence of long-term social interaction on chirping behavior, steroid levels, and neurogenesis in weakly electric fish. J. Exp. Biol. 216, 2434-2441.

Ebbeson, L.O.E., Braithwaite, V.A., 2012. Environmental effects on fish neural plasticity and cognition. J. Fish Biol. 81, 2151-2174.

Etheredge, R.I., Avenas, C., Armstrong, M.J., Cummings, M.E., 2018. Sex specific cognitive-behavioural profiles emerging from individual variation in numerosity discrimination in Gambusia affinis. Anim. Cogn. 21, 37-53.

Fernald, R.D., Maruska, K.P., 2012. Social information changes the brain. Proc. Natl. Acad. Sci. U.S.A. 109 (Suppl 2), 17194-17199.

Filby, A.L., Paul, G.C., Bartlett, E.J., van Look, K.J.W., Tyler, C.R., 2010. Physiological and health consequences of social status in zebrafish (Danio rerio). Physiol. Behav. $101,576-587$.

Fischer, S., Bessert-Nettelbeck, M., Kotrschal, A., Taborsky, B., 2015. Rearing-group size determines social competence and brain structure in a cooperatively breeding cichlid. Am. Naturalist. 186, 123-140.

Fisher, M.A., Oleksiak, M.F., 2007. Convergence and divergence in gene expression among natural populations exposed to pollution. BMC Genomics 8, 108.

Forlano, P.M., 2016. Hormone-dependent plasticity of auditory systems in fishes. In: Bass, A.H., Sisneros, J.A., Popper, A.N., Fay, R. (Eds.), Hearing and Hormones. Springer Handbook of Auditory Research, Vol. 57. Springer Science, New York, pp. 15-51.

Forlano, P.M., Bass, A.H., 2011. Neural and hormonal mechanisms of reproductive-re lated arousal in fishes. Horm. Behav. 59, 616-629.

Fox, H.E., White, S.A., Kao, M., Fernald, R.D., 1997. Stress and dominance in a social fish. J. Neurosci. 17, 6463-6469.

Francis, R.C., Soma, K., Fernald, R.D., 1993. Social regulation of the brain-pituitary-gonadal axis. Proc. Natl. Acad. Sci. U.S.A. 90, 7794-7798.

Fricke, H.W., 1973. Eine Fische-Seeigel-Partnerschaft. Untersuchungen optischer Reizparameter beim Formenerkennen. Mar. Bio. 119, 290-297.

Gerlai, R., 2014. Fish in behavior research: unique tools with a great promise!. J. Neurosci. Methods 234, 54-58.

Gilmour, K.M., Dibattista, J.D., Thomas, J.B., 2005. Physiological causes and consequences of social status in salmonid fish. Integr. Comp. Biol. 45, 263-273. 
Godwin, J., Thompson, R., 2012. Nonapeptides and Social Behavior in Fishes. Horm. Behav. 61, 230-238. https://doi.org/10.1016/j.yhbeh.2011.12.016.

Goodson, J.L., 2005. The vertebrate social behaviour network: evolutionary themes and variations. Horm. Behav. 48, 11-22.

Goodson, J.L., Bass, A.H., 2001. Social behavior functions and related anatomical characteristics of vasotocin/vasopressin systems in vertebrates. Brain Res. Rev. 35, 246-265. https://doi.org/10.1016/S0165-0173(01)00043-1.

Goodson, J.L., Kelly, A.M., Kingsbury, M.A., 2012. Evolving nonapeptide mechanisms of gregariousness and social diversity in birds. Horm. Behav. 61, 239-250.

Goodson, J.L., Kingsbury, M.A., 2011. Nonapeptides and the evolution of social group sizes in birds. Front. Neuroanat. 5, 13.

Goodson, J.L., Kingsbury, M.A., 2013. What's in a name? Considerations of homologies and nomenclature for vertebrate social behavior networks. Horm. Behav. 64, 103-112.

Greenwood, A.K., Wark, A.R., Fernald, R.D., Hofmann, H.A., 2008. Expression of arginine vasotocin in distinct preoptic regions is associated with dominant and subordinate behaviour in an African cichlid fish. Proc. R. Soc. B Biol. Sci. 275, 2393-2402.

Grober, M.S., Bass, A.H., 1991. Neuronal correlates of sex/role change in labrid fishes: LHRH-like immunoreactivity. Brain Behav. Evol. 38, 302-312.

Grober, M.S., Jackson, I.M.D., Bass, A.H., 1991. Gonadal steroids affect LHRH preoptic cell number in a sex/role changing fish. J. Neurobiol. 22, 734-741.

Grosenick, L., Clement, T.S., Fernald, R.D., 2007. Fish can infer social rank by observation alone. Nature 445, 429-432. https://doi.org/10.1038/nature05511.

Gross, M.R., Sargent, R.C., 1985. The evolution of male and female parental care in fishes. Am. Zool. 25, 807-822.

Grutter, A.S., Bshary, R., 2003. Cleaner wrasse prefer client mucus: support for partner control mechanisms in cleaning interactions. Proc. R. Soc. B 270, S242-S244.

Hall, Z.J., de Serrano, A.R., Rodd, F.H., Tropepe, V., 2014. Casting a wider fish net on animal models in neuropsychiatric research. Prog. Neuro-Psychopharmacol. Biol. Psychiatry 55, 7-15.

Herculano, A.M., Maximino, C., 2014. Serotonergic modulation of zebrafish behavior: towards a paradox. Prog. Neuropsychopharmacol. Biol. Psychiatry 55, 50-66.

Hofmann, H.A., Benson, M.E., Fernald, R.D., 1999. Social status regulates growth rate: consequences for life-history strategies. Proc. Natl. Acad. Sci. U.S.A. 96, $14171-14176$.

Holmqvist, B., Ekström, P., 1995. Hypophysiotrophic systems in the brain of the Atlantic salmon. Neuronal innervation of the pituitary and the origin of pituitary dopamine and nonapeptides identified by means of combined carbocyanine tract tracing and immunocytochemistry. J. Chem. Neuroanat. 8, 125-145.

Houde, A.E., 1997. Sex, Color, and Mate Choice in Guppies. Princeton University Press, Princeton, NJ.

Huhman, K.L., 2006. Social conflict models: Can they inform us about human psychopathology? Horm. Behav. 50, 640-646. https://doi.org/10.1016/j.yhbeh.2006.06. 022.

Iwata, E., Nagai, Y., Hyoudou, M., Sasaki, H., 2008. Social environment and sex differentiation in the false anemonefish, Amphiprion ocellaris. Zool. Sci. 25, 123-128.

Kalueff, A.V., Stewart, A.M., Gerlai, R., 2014. Zebrafish as an emerging model for studying complex brain disorders. Trends Pharmacol. Sci. 35, 63-75.

Kas, M.J.H., Krishnan, V., Gould, T.D., Collier, D.A., Olivier, B., Lesch, K.-P., Domenici, E., Fuchs, E., Gross, C.T., Castrén, E., 2011. Advances in multidisciplinary and crossspecies approaches to examine the neurobiology of psychiatric disorders. Eur. Neuropsychopharmacol. 21, 532-544. https://doi.org/10.1016/j.euroneuro.2010. 12.001 .

Kasper, C., Colombo, M., Aubin-Horth, N., Taborsky, B., 2018a. Brain activation patterns following a cooperation opportunity in a highly social cichlid fish. Physiol. Behav. 195, 37-47.

Kasper, C., Hebert, F.O., Aubin-Horth, N., Taborsky, B., 2018b. Divergent brain gene expression profiles between alternative behavioural helper types in a cooperative breeder. Mol. Ecol.

Keenlyside, M.H.A., 1979. Diversity and Adaptation in Fish Behaviour. Springer-Verlag, Berlin.

Kennedy, D.P., Adolphs, R., 2012. The social brain in psychiatric and neurological disorders. Trends Cogn. Sci. 16, 559-572. https://doi.org/10.1016/j.tics.2012.09.006.

Khoo, M.L., Das, S.K., Ghaffar, M.A., 2018. Growth pattern, diet and reproductive biology of the clownfish Amphiprion ocellaris in waters of Pulau Tioman, Malaysia. Egypt J. Aquat. Res.

Korzan, W.J., Robison, R.R., Zhao, S., Fernald, R.D., 2008. Color change as a potential behavioral strategy. Horm. Behav. 54, 463-470. https://doi.org/10.1016/j.yhbeh. 2008.05.006.

Kotrschal, A., Rogell, B., Maklakov, A.A., Kolm, N., 2012. Sex-specific plasticity in brain morphology depends on social environment of the guppy, Poecilia reticulata. Behav. Ecol. Sociobiol. 66, 1485-1492.

Krause, J., Ruxton, G.D., 2002. Living in groups. Oxford series in Ecology and Evolution. Oxford University Press, Oxford.

Krishnan, V., Han, M.-H., Graham, D.L., Berton, O., Renthal, W., Russo, S.J., LaPlant, Q., Graham, A., Lutter, M., Lagace, D.C., Ghose, S., Reister, R., Tannous, P., Green, T.A., Neve, R.L., Chakravarty, S., Kumar, A., Eisch, A.J., Self, D.W., Lee, F.S., Tamminga, C.A., Cooper, D.C., Gershenfeld, H.K., Nestler, E.J., 2007. Molecular adaptations underlying susceptibility and resistance to social defeat in brain reward regions. Cell 131, 391-404.

Krogh, A., 1929. The progress of physiology. Science 70, 200-204.

Kulczykowska, E., Cardoso, S.C., Gozdowska, M., André, G.I., Paula, J.R., Slebioda, M., Oliveira, R.F., Soares, M.C., 2015. Brain Levels of nonapeptides in four labrid fish with different levels of mutualistic behaviour. General Comp. Endocrinol. 222, 99-105.

Kullander, S.O., Ferreira, E.J., 2006. A review of the South American cichlid genus Cichla, with descriptions of nine new species (Teleostei: Cichlidae). Ichthyol Explor. Freshw. 17 (4), 289-398.

Lai, F., et al., 2017. Responses of neurogenesis and neuroplasticity related genes to elevated $\mathrm{CO}_{2}$ levels in the brain of three teleost species. Biol. Lett. 13.

Larson, E.T., Norris, D.O., Summers, C.H., 2003b. Monoaminergic changes associated with socially induced sex reversal in the saddle-back wrasse. Neuroscience 119, 251-263.

Larson, E.T., Norris, D.O., Grau, E.G., Summers, C.H., 2003a. Monoamines stimulate sex reversal in the saddleback wrasse. Gen. Comp. Endocrinol. 130, 289-298.

Larson, E.T., O'Malley, D.M., Melloni Jr, R.H., 2006. Aggression and vasotocin are associated with dominant-subordinate relationships in zebrafish. Behav. Brain Res. 167, 94-102.

Lim, M.M., Bielsky, I.F., Young, L.J., 2005. Neuropeptides and the social brain: potential rodent models of autism. Int. J. Dev. Neurosci. 23, 235-243. https://doi.org/10. 1016/j.ijdevneu.2004.05.006.

Liu, M., Wang, Y.Y., Shan, X.J., Kang, B., Ding, S.X., 2016. Primary male development of two sequentially hermaphroditic groupers, Epinephelus akaara and Epinephelus awoara (Perciformes: Epinephelidae). J. Fish Biol. 88 (4), 1598-1613.

Lo Nostro, F.L., Guerrero, G.A., 1996. Presence of primary and secondary males in a population of the protogynous Synbranchus marmoratus. J. Fish Biol. 49 (5), $788-800$.

Loveland, J.L., et al., 2014. Social status differences regulate the serotonergic system of a cichlid fish, Astatotilapia burtoni. J. Exp. Biol. 217, 2680-2690.

Lynch, K.S., Ramsey, M.E., Cummings, M.E., 2012. The mate choice brain: comparing gene profiles between female choice and male coercive poeciliids. Genes Brain Behav. $11,222-229$.

Ma, Y., et al., 2015. Electrical synapses connect a network of gonadotropin releasing hormone neurons in a cichlid fish. Proc. Natl. Acad. Sci. U.S.A. 112, 3805-3810.

Magurran, A.E., Maciás Garcia, C., 2000. Sex differences in behaviour as an indirect consequence of mating system. J. Fish Biol. 57, 839-857. https://doi.org/10.1111/j. 1095-8649.2000.tb02196.x.

Magurran, A.E., Seghers, B.H., 1994. Sexual conflict as a consequence of ecology: Evidence from guppy, Poecilia reticulata, populations in Trinidad. Proc. R. Soc. B Biol. Sci. 255, 31-36. https://doi.org/10.1098/rspb.1994.0005.

Maruska, K.P., et al., 2013b. Social opportunity causes rapid transcriptional changes in the social behavior network of the brain in an African cichlid fish. J. Neuroendocrinol. 25, 145-157.

Maruska, K.P., et al., 2013a. Social descent with territory loss causes rapid behavioral, endocrine, and transcriptional changes in the brain. J. Exp. Biol.

Maruska, K.P., 2014. Social regulation of reproduction in male cichlid fishes. Gen. Comp. Endocrinol. 207, 2-12.

Maruska, K.P., 2015. Social transitions cause rapid behavioral and neuroendocrine changes. Integr. Comp. Biol. 55, 294-306.

Maruska, K.P., Fernald, R.D., 2010a. Behavioral and physiological plasticity: rapid changes during social ascent in an African cichlid fish. Horm. Behav. 58, 230-240.

Maruska, K.P., Fernald, R.D., 2010c. Reproductive status regulates expression of sex steroid and GnRH receptors in the olfactory bulb. Behav. Brain Res. 213, 208-217.

Maruska, K.P., Fernald, R.D., 2010b. Steroid receptor expression in the fish inner ear varies with sex, social status, and reproductive state. BMC Neurosci. 11, 58.

Maruska, K.P., Fernald, R.D., 2013. Social regulation of male reproductive plasticity in an African Cichlid Fish. Integr. Comp. Biol. 207, 2-12.

Maruska, K.P., Fernald, R.D., 2014. Social regulation of gene expression in the African cichlid fish Astatotilapia burtoni. In: Canli, T. (Ed.), Handbook of Molecular Psychology. Vol. Oxford University Press, New York, N.Y., pp. 52-78.

Maruska, K.P., Fernald, R.D., 2018. Astatotilapia burtoni: a model system for analyzing the neurobiology of behavior. ACS Chem. Neurosci.

Maruska, K.P., Sisneros, J.A., 2015. Sex steroid-dependent modulation of acoustic communication systems in fishes. In: Ladich, F. (Ed.), Sound Communication in Fishes. Vol. Springer-Vienna, pp. 207-233.

Maruska, K.P., Carpenter, R.E., Fernald, R.D., 2012. Characterization of cell proliferation throughout the brain of the African cichlid fish Astatotilapia burtoni and its regulation by social status. J. Comp. Neurol. 520, 3471-3491.

Maruska, K.P., Butler, J.M., Field, K.E., 2018. Alternative reproductive phenotypes within species. In: Skinner, M.K. (Ed.), Encyclopedia of Reproduction, second ed. Academic Press: Elsevier, pp. 41-49.

Maximino, C., Silva, R.X. do C., da Silva, S. de N.S., Rodrigues, L. do S.D.S., Barbosa, H., de Carvalho, T.S., Leão, L.K.D.R., Lima, M.G., Oliveira, K.R.M., Herculano, A.M., 2015. Non-mammalian models in behavioral neuroscience: Consequences for biological psychiatry. Front. Behav. Neurosci. 9, 233. https://doi.org/10.3389/fnbeh. 2015.00233.

Maximino, C., Gomes, A.C., de Abreu, M.S., Cardoso, S., Lima-Maximino, M., Winberg, S., Soares, M.C., 2018. Profiles of cooperative brains: A discriminant analysis of cleaner and client fish monoaminergic responses to different social contexts. bioRxiv preprint. 326843.

McOmish, C.E., Burrows, E.L., Hannan, A.J., 2014. Identifying novel interventional strategies for psychiatric disorders: integrating genomics, "enviromics" and geneenvironment interactions in valid preclinical models. Br. J. Pharmacol. 171, 4719-4728. https://doi.org/10.1111/bph.12783.

Mendonça, R., Soares, M.C., Bshary, R., Oliveira, R.F., 2013. Arginine vasotocin neuronal phenotype and interspecific cooperative behaviour. Brain. Behav. Evol. 82, 166-176. https://doi.org/10.1159/000354784.

Messias, J.P.M., Santos, T.P., Pinto, M., Soares, M.C., 2016. Stimulation of dopamine D1 receptor improves learning capacity in cooperating cleaner fish. Proc. R. Soc. B 283, 20152272.

Miller, T.H., et al., 2017. Social status-dependent shift in neural circuit activation affects decision making. J. Neurosci. 37, 2137-2148. 
Moyle, P.B., Cech, J.J., 2000. Fishes an Introduction to Ichthyology, fourth ed. Prentice Hall.

Nelson, J.S., Grande, T.C., Wilson, M.V.H., 2016. Fishes of the world, 5th Ed. ed. John Wiley Sons Inc.

Neumeister, H., et al., 2010. Social and ecological regulation of a decision-making circuit. J. Neurophysiol. 104, 3180-3188.

Nikonov, A.A., et al., 2017. Reproductive and metabolic state differences in olfactory responses to amino acids in a mouth brooding African cichlid fish. J. Exp. Biol. 220, 2980-2992.

Nyman, C., Fischer, S., Aubin-Horth, N., Taborsky, B., 2017. Effect of the early social environment on behavioural and genomic responses to a social challenge in a cooperatively breeding vertebrate. Mol. Ecol. 26, 3186-3203.

O'Connell, L.A., Hofmann, H.A., 2012a. Evolution of a vertebrate social decision-making network. Science 336, 1154-1157.

Oates, J., Manica, A., Bshary, R., 2010. Roving decreases service quality in the cleaner wrasse Labroides bicolor. Ethology 116, 309-315.

O'Connell, L.A., Hofmann, H.A., 2012b. Social status predicts how sex steroid receptors regulate complex behavior across levels of biological organization. Endocrinology 153, 1341-1351.

Oldfield, R.G., Hofmann, H.A., 2011. Neuropeptide regulation of social behavior in a monogamous cichlid fish. Physiol. Behav. 102, 296-303.

Oliveira, R.F., 2009. Social behavior in context: hormonal modulation of behavioral plasticity and social competence. Int. Comp. Biol. 49, 423-440. https://doi.org/10. 1093/icb/icp055.

Oliveira, R.F., 2013. Mind the fish: zebrafish as a model in cognitive social neuroscience. Front. Neural Circuits 7 131. https://doi.org/10.3389/fncir.2013.00131.

Oliveira, R.F., Taborsky, M., Brockmann, H.J., 2008. Alternative Reproductive Tactics: An Integrative Approach. Cambridge University Press, Cambridge, MA.

Panksepp, J., Panksepp, J.B., Moskal, J.R., Kroes, R.A., 2002. Comparative approaches in evolutionary psychology: molecular neuroscience meets the mind. Neuroendocrinol. Lett. 23, 105-115.

Paula, J.R., Messias, J.P., Grutter, A.S., Bshary, R., Soares, M.C., 2015. The role of serotonin in the modulation of cooperative behaviour. Behav. Ecol. 26, 1005-1012.

Paull, G.C., Filby, A.L., Giddins, H.G., Coe, T.S., Hamilton, P.B., Tyler, C.R., 2010. Dominance hierarchies in Zebrafish (Danio rerio) and their relationship with reproductive success. Zebrafish 7, 109-117.

Pavlidis, M., Sundvik, M., Chen, Y., Panula, P., 2011. Adaptive changes in zebrafish brain in dominant-subordinate behavioral context. Behav. Brain Res. 225, 529-537. https://doi.org/10.1016/j.bbr.2011.08.022.

Perrone, R., Silva, A.C., 2018. Status-dependent vasotocin modulation of dominance and subordination in the weakly electric fish Gymnotus omarorum. Front. Behav. Neurosci. 12, 1

Pitcher, T.J., Green, D.A., Magurran, A.E., 1986. Dicing with a death: Predator inspection behaviour in minnow shoals. J. Fish Biol. 28, 439-448.

Qvarnström, A., Forsgren, E., 1998. Should females prefer dominant males? Trends Ecol. Evol. 13, 498-501.

Ravaglia, M.A., Lo Nostro, F.L., Maggese, M.C., Guerrero, G.A., Somoza, G.M., 1997. Characterization of molecular variants of $\mathrm{GnRH}$, induction of spermiation and sex reversal using salmon GnRH-A and domperidone in the protogynous diandric fish, Synbranchus marmoratus Bloch (Teleostei, Synbranchidae). Fish Physiol. Biochem. 16, 425-436.

Renn, S.C., Aubin-Horth, N., Hofmann, H.A., 2008. Fish and chips: functional genomics of social plasticity in an African cichlid fish. J. Exp. Biol. 211, 3041-3056.

Renn, S.C., O’Rourke, C.F., Aubin-Horth, N., Fraser, E.J., Hofmann, H.A., 2016. Dissecting the transcriptional patterns of social dominance across teleosts. Int. Comp. Biol. 56, $1250-1265$.

Ros, A.F.H., Lusa, J., Meyer, M., Soares, M., Oliveira, R.F., Brossard, M., Bshary, R., 2011. Does access to the bluestreak cleaner wrasse Labroides dimidiatus affect indicators of stress and health in resident reef fishes in the Red Sea? Horm. Behav. 59, 151-158.

Ross, R.M., 1986. Social organization and mating system of the Hawaiian reef fish Thalassoma duperrey (Labridae). Proc. Second Intl. Conf. Indo-pacific Fish 794-802.

Rüber, L., van Tassell, J.L., Zardoya, R., 2003. Rapid speciation and ecological divergence in the american seven-spined gobies (Gobiidae, Gobiosomatini) inferred from a molecular phylogeny. Evolution 57, 1584-1598.

Sadovy de Mitcheson, Y., Liu, M., 2008. Functional hermaphroditism in teleosts. Fish Fish. 9, 1-43.

Saito, D., Komatsuda, M., Urano, A., 2004. Functional organization of preoptic vasotocin and isotocin neurons in the brain of rainbow trout: Central and neurohypophysial projections of single neurons. Neuroscience 124, 937-984. https://doi.org/10.1016/ j.neuroscience.2003.12.038.

Sapolsky, R.M., 2005. The influence of social hierarchy on primate health. Science 308, 648-652.

Seehausen, O., Schluter, D., 2004. Male-male competition and nuptial-colour displacement as a diversifying force in Lake Victoria cichlid fishes. Proc. R. Soc. Lond. B 271, 1345-1353.

Semsar, K., Kandel, F.L., Godwin, J., 2001. Manipulations of the AVT system shift social status and related courtship and aggressive behavior in the bluehead wrasse. Horm. Behav. 40, 21-31.

Sgoifo, A., Koolhaas, J., De Boer, S., Musso, E., Stilli, D., Buwalda, B., Meerlo, P., 1999. Social stress, autonomic neural activation, and cardiac activity in rats. Neurosci. Biobehav. Rev. 23, 915-923.

Simpson, M.J.A., 1968. The display of the siamese fighting fish, Betta splendens. Anim. Behav. Monographs 1, 1-73.

Soares, M.C., 2017. The neurobiology of cooperation: the cleanerfish swims into the spotlight. Front. Behav. Neurosci. 11, 191.

Soares, M.C., Cardoso, S.C., Côté, I.M., 2007. Client preferences by caribbean cleaning gobies: food, safety or something else? Behav. Ecol. Sociobiol. 61, 1015-1022.

Soares, M.C., Bshary, R., Cardoso, S.C., Côté, I.M., 2008. Does competition for clients increase service quality in cleaning gobies. Ethology 114, 625-632.

Soares, M.C., Bshary, R., Côté, I.M., 2009. Cleaning in pairs enhances honesty in male cleaning gobies. Behav. Ecol. 20, 1343-1347. https://doi.org/10.1093/beheco/ $\operatorname{arp} 138$.

Soares, M.C., Oliveira, R., Ros, A.F.H., Grutter, A., Bshary, R., 2011. Tactile stimulation lower stress in fish. Nat. Commun. 2, 534.

Soares, M.C., Bshary, R., Mendonça, R., Grutter, A., Oliveira, R., 2012a. Neuropeptide modulation of cooperative behaviour: arginine vasotocin decreases prosocial behaviour in cleanerfish. PLoS One 7, e39583.

Soares, M.C., Bshary, R., Cardoso, S.C., Côté, I.M., Oliveira, R.F., 2012b. Face your fears: cleanerfish inspect predators despite being stressed by them. PLoS One 7, e39781.

Soares, M.C., Cardoso, S.C., Grutter, A., Oliveira, R., Bshary, R., 2014. Cortisol mediates cleaner wrasse switch from cooperation to cheating and tactical deception. Horm. Behav. 66, 346-1345.

Soares, M.C., de Paula, J.R., Bshary, R., 2016. Serotonin blockade delays learning performance in a cooperative fish. Anim. Cogn. 19, 1027-1030.

Soares, M.C., Cardoso, S.C., André, I.G., Mazzei, R., Morais, M., Gozdowska, M., Kalamarz-Kubiak, H., Kulczykowska, E., 2017a. Region specific changes in nonapeptide levels during client fish interactions with allopatric and sympatric cleaner fish. PLoS One 12, e0180290.

Soares, M.C., Santos, T.P., Santos, M.J.P.M., 2017b. Dopamine disruption increases cleanerfish cooperative investment to novel client partners. R. Soc. Open Sci. 4 , 160609.

Soares, M.C., Gerlai, R., Maximino, C., 2018a. The integration of sociality, monoamines and stress neuroendocrinology in fish models: applications in the neurosciences. J. Fish Biol.

Soares, M.C., Cardoso, S.C., Carvalho, T.S., Maximino, C., 2018b. The use of model fish as tools for research the biological mechanisms of cooperative behaviour: a future for translational research concerning social anxiety disorders? Progr. NeuroPsychopharmacol. Biol. Psychiatry 82, 205-215.

Sørensen, C., Nilsson, G.E., Summers, C.H., Øverli, Ø., 2012. Social stress reduces forebrain cell proliferation in rainbow trout (Oncorhynchus mykiss). Behav. Brain Res. 227, 311-318.

Sorensen, C., Overli, O., Summers, C.H., Nilsson, G.E., 2007. Social regulation of neurogenesis in teleosts. Brain Behav. Evol. 70, 239-246.

Stewart, A.M., Braubach, O., Spitsbergen, J., Gerlai, R., Kalueff, A.V., 2014. Zebrafish models for translational neuroscience research: from tank to bedside. Trends Neurosci. 37, 264-278.

Stewart, A.M., Ullmann, J.F.P., Norton, W.J.H., Parker, M.O., Brennan, C.H., Gerlai, R., Kalueff, A.V., 2015. Molecular psychiatry of zebrafish. Mol. Psychiatry 20, 2-17.

Striedter, G.F., Belgard, T.G., Chen, C., Davis, F.P., Finlay, B.L., Güntürkün, O., Hale, M.E., Harris, J.A., Hecht, E.E., Hof, P.R., Hofmann, H.A., Holland, L.Z., Iwaniuk, A.N., Jarvis, E.D., Karten, H.J., Katz, P.S., Kristan, W.B., Macagno, E.R., Mitra, P.P., Moroz, L.L., Preuss, T.M., Ragsdale, C.W., Sherwood, C.C., Stevens, C.F., Tsumoto, T., Wilczynski, W., 2014. NSF workshop report: discovering general principles of nervous system organization by comparing brain maps across species. Brain. Behav. Evol. 83, 1-8. https://doi.org/10.1159/000360152.

Suriyampola, P., Shelton, D., Shukla, R., Roy, T., Bhat, A., Martins, E.P., 2015. Zebrafish social behavior in the wild. Zebrafish 13, 1-8.

Taborsky, M., Limberger, D., 1981. Helpers in fish. Behav. Ecol. Sociobiol. 8, 143-214.

Taborsky, B., Oliveira, R.F., 2012. Social competence: an evolutionary approach. Trends Ecol. Evol. 27, 670-688.

Taborsky, B., Tschirren, L., Meunier, C., Aubin-Horth, N., 2013. Stable reprogramming of brain transcription profiles by the early social environment in a cooperatively breeding fish. Proc. R. Soc. B 280, 20122605.

Taylor, M.S., Hellberg, M.E., 2005. Marine radiations at small geographic scales: speciation in neotropical Reef Gobies (Elacatinus). Evolution 59, 374-385.

Tebbich, S., Bshary, R., Grutter, A.S., 2002. Cleaner fish labroides dimidiatus recognise familiar clients. Anim. Cogn. 5, 139-145.

Teles, M.C., Cardoso, S.D., Oliveira, R.F., 2016. Social plasticity relies on different neuroplasticity mechanisms across the brain social decision-making network in zebrafish. Front. Behav. Neurosci. 10, 16.

Todd, E.V., et al., 2018. Female mimicry by sneaker males has a transcriptomic signature in both the brain and the gonad in a sex-changing fish. Mol. Biol. Evol. 35, 225-241.

Triki, Z., Wismer, S., Levorato, E., Bshary, R., 2018. A decrease in the abundance and strategic sophistication of cleaner fish after environmental perturbations. Glob. Chang. Biol. 24, 481-489.

Valdimarsson, S.K., Metcalfe, N.B., 2001. Is the level of aggression and dispersion in territorial fish dependent on light intensity? Anim. Behav. 61, 1143-1149.

van der Bijl, W., Buechel, S. D., Kotrschal, A., Kolm, N., 2018. Revisiting the social brain hypothesis: contest duration depends on loser's brain size. BioRxiv preprint. doi: 10 . $1101 / 300335$.

Vaughan, D.B., Grutter, A.S., Costello, M.J., Hutson, K.S., 2016. Cleaner fishes and shrimp diversity and a re-evaluation of cleaning symbioses. Fish Fish. 18, 698-716.

von Uexküll, J., Mackinnon(Transl.), D.L., 1926. Theoretical biology. Trench, Trubner \& Co. Ltd. Harcourt, Brace \& Company, New York.

Wang, S., Ramsey, M.E., Cummings, M.E., 2014. Plasticity of the mate choice mind: evoking choice-like brain responses in coercive mating systems. Genes Brain Behav. 13, 365-375.

Warner, R.R., 1984. Mating behaviour and hermaphroditism in coral reef fishes. Am. Sci. $72,128-136$.

Warner, R.R., Swearer, S.E., 1991. Social control of sex change in the bluehead wrasse, Thalassoma bifasciatum (Pisces: Labridae). Biol. Bull. 181, 199-204.

Whitaker, K.W., et al., 2011. Serotonergic modulation of startle-escape plasticity in an 
African cichlid fish: a single-cell molecular and physiological analysis of a vital neural circuit. J. Neurophysiol. 106, 127-137.

White, J.W., Grigsby, C.J., Warner, R.R., 2007. Cleaning behaviour is riskier and less profitable than an alternative strategy for a facultative cleaner fish. Coral Reefs. 26, 87-94.

Winberg, S., Winberg, Y., Fernald, R.D., 2008. Effect of social rank on brain monoaminergic activity in a cichlid fish. Brain. Behav. Evol. 49, 230-236. https://doi.org/ 10.1159/000112994.

Wingfield, J.C., Sapolsky, R.M., 2003. Reproduction and resistance to stress: when and how. J. Neuroendocrinol. 15, 711-724.

Wismer, S., Pinto, A.I., Vail, A.L., Grutter, A.S., Bshary, R., 2014. Variation in cleaner wrasse cooperation and cognition: potentially caused by developmental environment? Ethology 120, 519-531.

Wong, M., Balshine, S., 2011. The evolution of cooperative breeding in the African cichlid fish, Neolamprologus pulcher. Biol. Rev. Camb. Philos. Soc. 86, 511-530.

Wong, R.Y., Cummings, M.E., 2014. Expression patterns of neuroligin-3 and tyrosine hydroxylase across the brain in mate choice contexts in female swordtails. Brain Behav. Evol. 83, 231-243.

Wong, R.Y., Ramsey, M.E., Cummings, M.E., 2012. Localizing brain regions associated with female mate preference behavior in a swordtail. PLoS One 7, e50355.

Zupanc, G.K., Sîrbulescu, R.F., 2011. Adult neurogenesis and neuronal regeneration in the central nervous system of teleost fish. Eur. J. Neurosci. 34, 917-929. 